\title{
The Long-term Rate and Interest Rate Volatility in Monetary Policy Transmission*
}

\author{
Zhengyang Chen \\ University of Texas at Dallas
}

This Draft: September 30, 2019

\begin{abstract}
The federal funds rate became uninformative about the stance of monetary policy from December 2008 to November 2015. During the same period, unconventional monetary policy actions, like large-scale asset purchases, show the Federal Reserve's intention to depress longer-term interest rates. This paper considers a long-term real interest rate as an alternative monetary policy indicator in a structural VAR framework. Based on an event study of FOMC announcements, I advance a novel measure of long-term interest rate volatility with important implication for monetary policy identification. I find that monetary policy shocks identified with this volatility measure drive significant swings in credit market sentiments and real output. In contrast, monetary policy shocks identified by otherwise standard unexpected policy rate changes lead to muted responses of financial frictions and production. Our results support the validity of the risk-taking channel and suggest an indispensable role of financial markets in monetary policy transmission.
\end{abstract}

Keywords: Monetary policy transmission; Risk-taking channel; Structural vector autoregression; High-frequency identification

JEL classification codes: E3, E4, E5

*Acknowledgments deferred for review. 


\section{Introduction}

Conventionally, monetary economists use changes in short-term interest rates, e.g., the federal funds rate for the United States, to gauge monetary policy stances and identify monetary policy shocks. The Taylor rule, in its various iterations, provides theoretical support for these practices. However, from December 2008 to November 2015, when the federal funds rate essentially collapsed to its zero lower bound (ZLB), the measurement of monetary policy experiences two challenges, such as an uninformative short-term rate and the quantification of unconventional monetary policy tools. Both of these impose question marks on the validity of a Taylor rule strategy in monetary policy identification.

One potential solution is to construct measures sensitive to policy rate changes during the non-ZLB period and otherwise unconstrained by the ZLB. For instance, Krippner (2013), Lombardi and Zhu (2014) and Wu and Xia (2016) use parametric estimations from a factor approach to construct "shadow policy rates" that can accommodate negative values and may give insight on how far the nominal short-term rate would reach if unconstrained by the ZLB. Alternatively, Freedman (1994) proposes a Monetary Conditions Index, which is derived from a linear combination of short-term interest rates and exchange rates, to infer monetary policy actions. However, without a proper identification scheme, this measure has some shortcomings as the exchange rate is subjected to influences other than monetary policy decisions. Some economists revisit monetary aggregates and supply evidence that a superlative measure of money (i.e., Divisia monetary index) can properly reflect the stance of monetary policy in structural VAR (SVAR) models, especially in the aftermath of the 2007 financial crisis (Keating et al., 2014, 2019).

Those alternative measures are based on the common wisdom that monetary policy only exerts influence through short-term rates. However, unconventional monetary policy tools extensively applied during the ZLB period may have affected longer-term interest rates. For instance, the Federal Reserve increasingly relies on communication, such as forward guidance, to implement monetary policy, particularly since the possibilities to steer the economy via short-term rate policy has been limited by the effective zero lower bound (refer to Couré (2017) and Blinder (2018)). Woodford (2012) and Swanson and Williams (2014) show that the forward guidance strategy affects the two-year-and even longer maturityTreasury yields through guiding expectations on future policy rates. Another example of these unconventional tools is a series of large-scale asset purchases (LSAP) programs between late 2008 and October 2014 that the Federal Reserve conducted. These programs expanded the Federal Reserve's balance sheet with direct purchases of longer-term Treasury securities and mortgage-backed securities in private markets. The explicit intention was to depress 
longer-term interest rates. An increasing amount of researches demonstrate the significant impact of LSAPs on long-term Treasury yields ${ }^{1}$. Former FOMC Chair Bernanke summarized that

"Forward rate guidance affects longer-term interest rates primarily by influencing investors' expectations of future short-term interest rates. LSAPs, in contrast, most directly affect term premiums." Bernanke (2013)

We suggest a medium- to long-term interest rate as an alternative monetary policy indicator with three main considerations. First, we want this measure to be sensitive to variation in short-term rates. Second, this measure should be unrestricted by the ZLB. Third, it should reflect the non-negligible impact of unconventional monetary policy tools with particular attention for the long end of the yield curve.

Admittedly, quantifying monetary policy actions through longer-term rates is a relatively new approach, though it has been gradually gaining attention. Swanson and Williams (2014), Hanson and Stein (2015) and others argue that Treasury yields with more than two-year maturities may properly reflect the impact of forward guidance. In an SVAR model, Wright (2012) identifies the impact of LSAPs through heteroskedasticity of the reduced-from residual from the 10-year Treasury yield. Weale and Wieladek (2016) include the 10-year Treasury yield in an SVAR model to show how purchases of government bonds by the Bank of England and the Federal Reserve affect long-term yields. Gurkaynak et al. (2004) and Swanson (2017) extract factors from prices of financial assets, including a variety of long-term securities, to measure the effects of policy rate changes, forward guidance, and LSAPs. They specifically identify the factor most closely related LSAPs as the only one that affects long-term interest rates. DSGE models on monetary transmission are still preliminary in depicting the role of longer-term rates in transmitting monetary policy to the economy (please refer to the Christiano et al. (2010) review). To our knowledge, this is the first paper that explicitly considers a long-term rate as the policy indicator in an SVAR model.

The critical challenge in considering a long-term interest rate - such as the 10-year real yield - as the policy indicator lies in the identification of exogenous monetary policy actions from fluctuations in long-term rates.

Our approach stems from an event study of FOMC announcements and a high-frequency identification approach in SVAR models. Kuttner (2001) constitute an event study from shifts of the spot-month federal funds future rate in each FOMC announcement date. This is done in order to gauge unexpected monetary policy actions (see also Gürkaynak et al.

\footnotetext{
${ }^{1}$ Please refer to Gagnon (2010), Gagnon et al. (2011), d'Amico et al. (2012), Rosa (2012), Swanson (2015) and more.
} 
(2005), Hamilton (2008) and Campbell et al. (2012)). More recently, Gertler and Karadi (2015) advance a VAR identification strategy in which unexpected changes in the federal funds futures rate, captured by an event-study approach, facilitates the identification of monetary policy shocks from movements in the policy indicator (the one-year Treasury yield). However, simply applying the aforementioned strategy to identify policy shocks in a longterm rate could be counterproductive. Figure 1 highlights that the 10 -year rate seems to be considerably more volatile than the federal funds rate and the one-year Treasury yield. It may be conjectural to assert that unexpected funds rate changes should reflect the overall impacts of FOMC announcements on a long-term rate. In the alternative, we investigate other institutional and theoretical perspectives of monetary policy transmission that extend beyond traditional short-term offer rates.

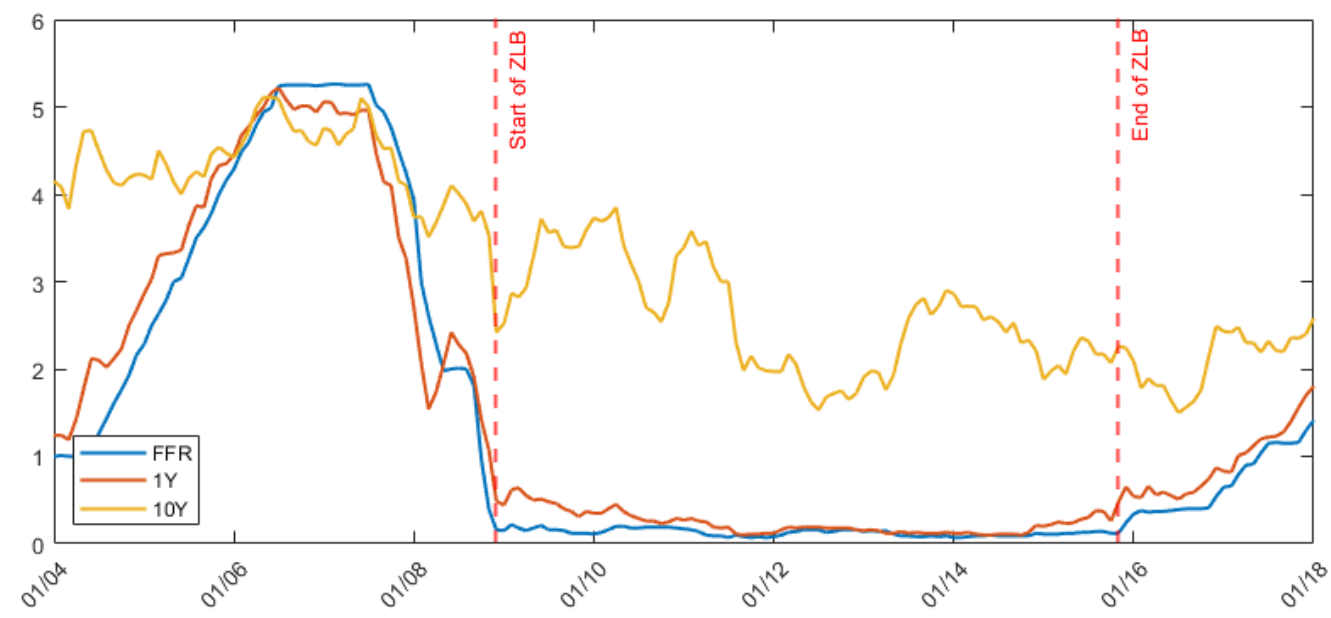

Figure 1: Federal Funds Rate, 1yr and 10yr Treasury Yields

Institutionally, the Federal Reserve seems to maintain different degrees of intention on the two ends of the yield curve. Interest rate volatility is frequently under-explored in the context of monetary policy.

For the short end of the yield curve, it might be reasonable to allow for a level change of the short-term rate, within a tight window around FOMC announcements, to fully represent the exogenous monetary policy actions. This is an appropriate mechanism because of the Federal Reserve's explicit commitment to the policy rate target. The near-term expectation of the federal funds rate may immediately adjust to a newly announced target if the Federal Reserve constantly fine tunes the discrepancy of the policy rate from its target range via 
open market operations. As a result, the fluctuation of the policy rate, ex-post an FOMC meeting, is uninformative in assessing the effects of policy actions ${ }^{2}$.

The Federal Reserve does not explicitly express and maintain a target for any long-term rates. After an FOMC press release, the statement may induce heteroskedastic variation in long-term rate fluctuations around ex-post steady states. In other words, when analyzing the influence of an FOMC decision, the investigation should not be restricted to changes in the expected levels of long rates, but also shed light on shifts in expected volatility.

Recent theoretical developments in the topic of monetary transmission reconfirm our focus on the critical but less explored role of interest rate volatility. Rajan (2006) and Adrian and Shin (2008) discuss the impact of monetary policy on the risk-taking behavior of financial intermediaries. Risk perception and risk tolerance of financial intermediaries contribute to their varying risk-taking behavior and thus affect economic activity. Borio and Zhu (2012) formally propose the concept of the risk-taking channel and review how monetary policy affects banks' perceived risk. The countercyclical nature of perceived risk in the risk-taking channel is isomorphic to the external financing premium in a financial accelerator model (Bernanke et al., 1999). It is relatively common in the literature to utilize the volatility implied by option prices to gauge the perceived risk in a given market $^{3}$.

Given these sparse but interrelated studies, we hypothesize that interest rate volatility plays a role in the monetary policy transmission, especially in the risk-taking channel. However, to my knowledge, at the time of this writing, there is no existing event study measure that quantifies the impact of monetary policy announcements on expectations of the volatility of long-term rates. Furthermore, little effort has been dedicated to investigating the potential role of movements in the second moment of a long-term rate in motivating monetary policy shocks and driving innovations in the long-term rate.

Overall, we center attention on how monetary policy transmits to the yield curve, especially to long-term rates, and, in turn, how it propagates to aggregate economic activities. We introduce a long-term real rate and an event study measure with the implied volatility of a long-term nominal rate into an otherwise standard SVAR model.

In our econometric technique, selecting a long-term real rate as a policy indicator affords us some versatility to include more comprehensive information content from FOMC statements. We identify monetary policy shocks with the assistance of high-frequency external

\footnotetext{
${ }^{2}$ Bundick et al. (2017) construct an implied volatility about short-term interest rates via VIX methodology. However, instead of identifying monetary policy shocks, they identify a monetary policy uncertainty shock which does not contemporaneously respond to a policy rate shock under a recursive ordering.

${ }^{3}$ Please refer to Fleming et al. (1995), Fleming (1998) and Christensen and Prabhala (1998) for perceived risk in stock market, and Carlson et al. (2005), Emmons et al. (2006) and Swanson (2006) for perceived uncertainty in policy rates
} 
instruments. We construct event studies respectively from movements of the spot-month funds future rate and variation in the implied volatility of 10-year rate around each FOMC announcement. From this construct, we generate two policy instruments which are time series of policy rate surprises and time series of volatility surprises. The SVAR impulse responses show that both policy rate surprises and volatility surprises can significantly stimulate fluctuations in the long-term real rate and the price level without incurring the price puzzle put forth by Eichenbaum (1992), but only the latter drives swings of financial frictions and output. These findings support the financial accelerator models (Bernanke et al., 1999) in which financial intermediations amplify the policy impact on economic activity. Our results also question the cost-of-capital effect in Neoclassical theory of investment since production seems muted to the policy-rate-induced change in the long-term real rate. In terms of monetary transmission channels, we obtain evidence in support of the risk-taking channel but fail to observe the validity of the conventional Keynesian interest rate channel.

This paper extends an SVAR model to examine the validity of different mainstream monetary transmission channels within a comparable framework. Furthermore, we generate the first measure of monetary-policy-induced changes in the expected volatility of monetary policy shocks in the long run. This measure has the potential to be an alternative monetary policy surprise to indicate the risk-side impact of monetary policy. Lastly, we observe relatively independent monetary policy transmission mechanisms through the two ends of the yield curve. This finding may open a window for refined monetary policy identifications respectively for short- and long-term interest rates.

This research also connects with a growing topic focusing on the linkage between shortand long-term rates surrounding FOMC announcements (Cochrane and Piazzesi, 2002; Gürkaynak et al., 2005). Hanson and Stein (2015) suggest a story of yield-searching investors to explain how a change in the short-term rate induced by a policy rate movement contributes to the instant shift of the term premia of long-term real rates. However, they make an assumption to simplify the transmission from monetary policy to long-term rates; that changes of short-term rates can properly assess the full information content of FOMC announcements. This paper relaxes this assumption and further asks a more structural question: which components of monetary policy propagate to the economy through long-term rates. Our results are consistent with previous findings that an unexpected policy rate change affects long-term nominal and real rates, but additionally, it reveals that the interest rate volatility, rather than the policy rate, plays the primary role in transmitting the effect of monetary policy to economic activity through long-term rates.

The rest of the paper proceeds as follow. Section Two presents our econometric framework of structural VAR model and identification strategy. Section Three introduces the data 
and sample, especially the policy indicator and policy instruments. Section Four lays out the empirical results, and Section Five discusses their implications on the monetary policy transmission. Section Six offers a detailed procedure of the construction of the volatility surprise for readers' reference, and Section Seven concludes.

\section{Econometric Framework}

Our econometric analysis is based on an SVAR model with an intention to investigate the monetary policy transmission mechanism, through which monetary policy affects economic activity. We select a high-frequency identification (HFI) scheme to identify monetary policy shocks.

The HFI approach is developed on Stock and Watson (2012), Mertens and Ravn (2013) and Gertler and Karadi (2015). It identifies monetary policy shocks with the assistance of external instrumental variables. This method is originally designed to deal with the sensitivity of the included endogenous financial variable to structural shocks (Bagliano and Favero, 1999; Cochrane and Piazzesi, 2002; Faust et al., 2004; Mertens and Ravn, 2013). In an SVAR model with financial variables, recursive timing restrictions in the conventional Cholesky identification should be questionable. It is arduous to justify that those financial variables, given their high-frequency fluctuations, do not contemporaneously respond to certain structural shocks. In contrast, HFI does not restrict the timing of contemporaneous responses.

A feature of the external instrument identification scheme is the separation of policy instruments and policy indicators. A policy instrument is captured in the high-frequency financial data, such as the spot-month federal funds future rate or the option-implied volatility of the 10-year rate, by imposing an "adequately small" time window on each FOMC meeting announcement. Policy instruments produced by this event study manner measure the unexpected impact of monetary policy caused by FOMC announcements and carry relevance to monetary policy shocks. Furthermore, if time windows are properly designed to cope with the impact of economic news, those instruments should be orthogonal to other structural economic shocks. A policy indicator is one of the endogenous variables in a lower-frequency VAR, indicating monetary policy stances. A reduced-form residual in the policy indicator may be attributed to monetary policy shocks as well as accommodative policy actions and other structural shocks. To identify monetary policy shocks, a policy instrument acts as an instrumental variable for the policy indicator to estimate the unbiased contemporaneous responses of the policy indicator to structural monetary policy shocks. This method combines the features of event studies with structural identification in SVAR models. 
However, previous studies like Gertler and Karadi (2015) limit the potential of this framework by implicitly making two relatively strict assumptions; that monetary policy takes effect through short-term rates, and that monetary policy is confined to policy rate changes. We relax those restrictions by proposing a long-term interest rate as a policy indicator and constructing a policy instrument concerning the risk-side implication of each entire FOMC announcement.

On one hand, there is an increasing amount of evidence suggesting that the monetary policy affects long-term rates in complicated manners. There are at least four avenues discussed in the literature. First, the conventional Keynesian interest rate channel suggests that the policy rate changes may pass through to long-term nominal rates based on the expectations theory of term structure, and may further affect long-term real rates because of sticky price setting in Keynesian models. Second, unexpected changes of the policy rate lead to variation in the term premia of distant forward rates according to Jorda (2005), Hanson and Stein (2015) and others. Third, unconventional monetary policy tools, especially LSAPs, affects longer-term rates by purchasing longer-term securities in private markets. Lastly, monetary policy and Federal Reserve's communication with the public may influence the risk perception of financial intermediaries and affect long-term real rates via variation in risk-taking behavior such as long-term lending (Borio and Zhu, 2012). Although long-term rates seem to be unavoidable nodes in the policy transmission, they are not included in the state-of-art monetary VAR models, such as those in Christiano et al. (1999). We possess extremely limited understanding of the role of long-term rates in the "black box" between monetary policy and economic activity. This paper sheds light on this black box by taking a long-term real rate as a potential policy indicator. It may reflect the full spectrum of the aforementioned impact of monetary policy on long-term rates.

On the other hand, studies on the risk-taking channel attract increasing attention but this channel is seldom identified in a VAR model. There are extensive empirical studies on the linkage of monetary policy and bank's risk-taking behavior ${ }^{4}$. However, without a structural model, it is unpractical to investigate the endogenous interactions among monetary policy, risk perception in financial markets and economic activity. This paper generates a time series of monetary surprises, that capture how each FOMC meeting announcement, instead of each policy rate change, shifts the near-term expectation of long-term interest rate volatility. Then, we utilize these surprises in interest rate volatility to identify monetary policy shocks in the risk-taking channel.

\footnotetext{
${ }^{4}$ Please refer to Altunbas et al. (2009), Gambacorta (2009), Delis et al. (2012), Bruno and Shin (2015) and Dell'Ariccia et al. (2017).
} 
In summary, our SVAR framework not only allows for influences of monetary policy on the long end of the yield curve, but also consider the entire impact of each FOMC statement on risk perception in bond markets.

\subsection{General Econometric Representation}

Let $Y_{t}$ be a vector of $\mathrm{n}$ economic and financial variables. $A$ and $C_{j} \forall j \geqslant 1$ are conformable coefficient matrices, while $\epsilon_{t}$ is a vector of structural white noise shocks. Matrix $A$ denotes the contemporaneous interactions among endogenous variables. The structural shocks are orthogonal to each other and normalized to one standard deviation. Then the general structural form of the VAR model is given by

$$
A Y_{t}=\sum_{j=1}^{p} C_{j} Y_{t-j}+\epsilon_{t}
$$

The straightforward estimation of structural form VAR may incur the endogeneity issue. Pre-multiplying both sides of the equation with $A^{-1}$ derives the reduced form representation

$$
Y_{t}=\Sigma_{j=1}^{p} B_{j} Y_{t-j}+u_{t}
$$

where $u_{t}$ is the vector of reduced form residuals. Parameters in reduced form VAR can be estimated by equation-by-equation ordinary least square regressions. Since the structural shocks are of the concern, the reduced form residuals are related to the structural shocks in the following mapping function

$$
u_{t}=S \epsilon_{t}
$$

with $B_{j}=A^{-1} C_{j}$ and $S=A^{-1}$. Matrix $S$ is the mapping from structural shocks to reduced form residuals. By normalizing structural shocks $\epsilon_{t}$ to an identity matrix, the reduced form variance-covariance matrix is

$$
E_{t}\left[u_{t} u_{t}^{\prime}\right]=S S^{\prime}=\Sigma
$$

Consider $y_{t}^{p} \in Y_{t}$ as the policy indicator and $\epsilon_{t}^{p}$ as the associated structural policy shock. Then, let $\mathrm{s}(n \times 1)$ denote the column in matrix $\mathrm{S}$ that corresponds to the impact of structural policy shocks $\epsilon_{t}^{p}(1 \times 1)$ on elements in the vector of reduced form shocks $u_{t}$. Since our primary

question is how economic and financial variables in $Y_{t}$ respond to monetary policy shocks, we thus need to estimate parameters in the following equation. We only identify the monetary policy shocks and impose no restrictions on other structural parameters.

$$
Y_{t}=\Sigma_{j=1}^{p} B_{j} Y_{t-j}+s \epsilon_{t}^{p}
$$


The difficulty of identification lies in the estimation of the mapping vector $s$ that is related to monetary policy shocks. The reduced form residual of policy indicator $u_{t}^{p}$ is estimable via OLS regression in the policy indicator equation, but it requires restrictions to identify the portion of $u_{t}^{p}$ driven by structural monetary policy shocks and exogenous to other economic shocks.

Identification by external instrument considers monetary policy surprises constructed through an event study method in high-frequency data as the exogenous component of monetary policy. Event-study monetary policy surprises are qualified as policy instruments $Z_{t}$ if they are strongly correlated with monetary policy shocks $\epsilon_{t}^{p}$ (relevance condition), but orthogonal to other structural shocks $\epsilon_{t}^{q}$ (exogeneity condition).

$$
\begin{aligned}
& E\left[Z_{t} \epsilon_{t}^{p \prime}\right]=0 \\
& E\left[Z_{t} \epsilon_{t}^{q^{\prime}}\right] \neq 0
\end{aligned}
$$

The two-stage identification process is similar to the 2-stage least square regression in univariate analyses. The reduced form residual in the policy equation $u_{t}^{p}$ is endogenously related to other reduced form residuals $u_{t}^{q}$ due to the contemporaneous interactions among variables in $Y_{t}$. In the first stage regression, we use externally identified monetary policy surprises as policy instruments to tease out the component of $u_{t}^{p}$ affected by contemporaneous monetary policy shocks $\epsilon_{t}^{p}$.

$$
u_{t}^{p}=\gamma Z_{t}+\epsilon_{t}
$$

In the second stage, we obtain the relationship between responses of other included variables and that of policy indicator to a unit increase of monetary policy shocks by equation (9). $s^{q}$ link the contemporary variation of non-policy variables $u_{t}^{q}$ to a unit of monetary policy shock $\epsilon_{t}^{p}$ and $s^{p}$ denote how the VAR residual in the policy indicator equation react to one unit of $\epsilon_{t}^{p}$. Since the reduced form residual $u_{t}^{p}$ may be partially endogenous to $u_{t}^{q}$, we use the exogenous component $\gamma Z_{t}\left(\hat{u_{t}^{p}}\right)$ derived from the first stage to acquire unbiased estimation of relative changes of $u_{t}^{q}$ to $u_{t}^{p}$ in response of a unit increase of monetary policy shock $\frac{s^{q}}{s^{p}}$.

$$
u_{t}^{q}=\frac{s^{q}}{s^{p}} \hat{u_{t}^{p}}+e_{t}
$$

With the estimated $\frac{s^{q}}{s^{p}}$, reduced form residuals $u_{t}$ and the reduced form variance-covariance matrix $\Sigma$, we thus derive the estimation of $s^{p}$ and $s^{q} .^{5}$

\footnotetext{
${ }^{5}$ See Appendix A for more details about the algorithm for identification.
} 
Importantly, this econometric framework imposes no restrictions that the policy indicator must be a short-term rate, and that policy instrument should be a variable describing behavior in the policy rate.

\subsection{Identify Monetary Policy Shocks in the Risk-taking Channel}

In the risk-taking channel, monetary policy shocks motivate adjustments of financial intermediaries' risk perception. To distinguish from the default risk which bears more relationship with the operation in the private sector, the risk specified here is the interest rate risk $^{6}$, akin to the anticipated volatility associated with future monetary policy shocks in the long run. Based on individuals' risk interpretations of monetary policy announcements, those financial intermediaries shall decide the volume of their lending (risk-taking) activities and term premium on their baseline long-term lending rates. For instance, a relative volatile monetary policy environment may introduce additional uncertainty in banks' investment decision, affecting lending activities. Unexpected changes of the policy rate may fall short in identifying monetary policy shocks in the risk-taking channel due to its lack of risk implication and the loss of richer information content in FOMC statements besides policy rate movements.

We consider three criteria under relevance and exogeneity conditions for a policy instrument to qualify in identifying policy shocks in the risk-taking channel. In terms of relevance to monetary policy shocks, it should be adequately comprehensive to include the entire information content of FOMC announcements and be confined to bonds markets as the Federal Reserve primarily exerts impact on interest rates. On the point of exogeneity, it should be exogenous to stances of the public who has no access to the Federal Reserve's private information. Thus, the captured movements are only sourced from the Federal Reserve's private information set. With an event study approach, we generate the time series of volatility surprises which capture the risk-side implication of FOMC announcements for a representative long-term bond market. Section Six provides a detailed road map of generating this risk-related policy instrument.

The equation (11) - (13) shows in detail how to use event study method to identify the exogenous movements in perceived risk in daily data.

$$
\begin{array}{r}
V O L_{t}=d_{t}^{F O M C}\left[E_{1, t} \sigma_{t+30}^{p}-E_{0, t} \sigma_{t+30}^{p}\right] \\
\text { where }\left[\sigma_{t+30}^{p}\right]^{2}=\sigma_{t+30}\left(s^{p} \epsilon_{t}^{p}\right)^{2}+\sigma_{t+30}\left(s^{q} \epsilon_{t}^{q}\right)^{2}
\end{array}
$$

\footnotetext{
${ }^{6}$ Interest rate risk is defined as the chance that investments in bonds will suffer due to unexpected interest rate changes with known distribution. Interest rate uncertainty is mainly referred to as the unpredictability of monetary policy decisions.
} 
On the left-hand side of equation (11), a volatility surprise, $V O L_{t}$, captures variation in the 30-day expectation in volatility of the policy indicator induced by monetary policy and unexpected by financial markets. The right-hand side of the equation demonstrates the event study approach. The expectation operator $E_{1}$ (and $E_{0}$ ) denote the expectation based on the information set before (and after) the release of an FOMC statement. The volatility of policy indicator in the ensuring 30 days after the FOMC announcement is noted as $\sigma_{t+30}^{p}$. It is partitioned into two components respectively ascribed to different structural shocks, i.e. monetary policy shocks and non-policy shocks. Given that the measuring scope are principally identical for the two 30-day implied volatility shortly before and after an announcement, We consider the 30 days in the volatility measurement unchanged. Let $d_{t}^{F O M C}$ be the time dummy for FOMC announcements; which equals 1 when there is an FOMC announcement and, otherwise, equals zero.

We inherent the assumption from Wright (2012) that the information content of monetary policy statements is the source of the higher volatility of monetary policy shocks $\sigma\left(\epsilon_{t}^{p}\right)$ on FOMC announcement days. This implies that the non-policy structural shocks $\epsilon_{t}^{p}$ are randomly distributed on the timeline and their contributions to the volatility of policy indicator are stable shortly before and after one announcement. As the impact of non-policy structural shocks is essentially canceled out when taking the difference in an event study approach, we retain changes in the volatility of monetary policy shocks in volatility surprises as $s^{p}$ is treated as a constant parameter. As shown in equation (13), volatility surprises indicate variation, due to FOMC announcements, in the expected volatility of monetary policy shocks. If the policy indicator is a long-term rate, then volatility surprises monitor changes in the expected volatility of monetary policy shocks in the long run.

$$
V O L_{t}=s^{p} d_{t}^{F O M C} E_{t}\left(\Delta \sigma_{t+30}\left(\epsilon_{t}^{p}\right) \mid \Omega_{1}-\Omega_{0}\right)
$$

With the assistance of volatility surprises, we combine the identification by external instruments with identification by heteroskedasticity to identify monetary policy shocks in the SVAR model.

Identification by heteroskedasticity is introduced by Rigobon (2003) and further applied by Rigobon and Sack (2003), Rigobon and Sack (2004) and others. One strategy proposed by Wright (2012) relies on the observation that, on the dates with FOMC announcements, the variance of monetary policy shocks is different from that on the dates without announcements.

Let $\sigma_{1}$ and $\sigma_{0}$ be the volatility of monetary policy shocks respectively in FOMC announcement and non-announcement dates. And $\Sigma_{1}$ and $\Sigma_{0}$ are the variance-covariance matrices of 
reduced form errors estimated separately for those two circumstances. Vector $s$ represents how reduced form residuals react to a unit increase in structural monetary policy shocks $\epsilon_{t}^{p}$. The assumption can be expressed by

$$
\Sigma_{1}-\Sigma_{0}=s s^{\prime} \sigma_{1}^{2}-s s^{\prime} \sigma_{0}^{2}=s s^{\prime}\left(\sigma_{1}^{2}-\sigma_{0}^{2}\right)
$$

As $\Sigma_{1}$ and $\Sigma_{0}$ can be estimated via equation-by-equation OLS regressions and $\sigma_{1}^{2}-\sigma_{0}^{2}$ is assumed to be a constant, the vector $s$ is estimable by a distance minimization function.

This identification is advantageous over the identification by external instruments in two points. First, this approach is associated with the measurement of risk if considering changes in the volatility or variance of monetary policy shocks in the context of interest rate risk. This may be a probable approach to incorporate the risk factor into the identification of monetary policy shocks. Second, it enables us to identify the impact of entire monetary policy, rather than only account for policy rate changes. This approach does not require full knowledge of how each component of monetary policy affects the volatility before analyzing the influence of monetary policy in integral.

However, this heteroskedasticity approach falls short to our need in three aspects. First, since the identification is achieved in daily data, the resulting monetary policy shocks are unable to interfere with macroeconomic variables which are usually in monthly or even lower frequency. Second, the varying volatility or variance on announcement days may not only show the influence of monetary policy, but also reflects the pre-FOMC-announcement drift in the volatility driven by the occurrence of FOMC events ${ }^{7}$. Monetary policy shocks identified by the variance on announcement dates may not precisely reflect monetary policy stances. Third, the realized volatility may not be a good measure of perceived risk, since the realized volatility is settled and no longer risky for market participants.

To deal with those shortcomings, we combine the heteroskedasticity approach with the external instrument method by three modifications on the former.

First, we allow heteroskedasticity among all FOMC announcement dates. Specifically, instead of identifying the mapping vector $s$ in a lump sum, we identify $s^{p}$, the impact of a oneunit monetary policy shock $\epsilon_{t}^{p}$ on the policy indicator with the volatility surprise being the instrumental variable. More accurate identification is achieved because volatility surprises update changes in the volatility for each FOMC announcement relative to an adjacent nonannouncement date. In comparison, Wright (2012) draw attention to the different variances for FOMC announcement and non-announcement dates. Furthermore, by converting the

\footnotetext{
${ }^{7}$ Please see the detail of pre-FOMC-announcement drift in Section Six.
} 
event-study time series of volatility surprises into the monthly one, we overcome the gap of data frequency between event study time series and monthly VAR model.

Second, as to the policy instrument, we apply a 4-day time window in order to exclude the impact of the event-driven, pre-FOMC-announcement drift of interest rate volatility and retain the relevance of volatility surprises to monetary policy actions (please refer to Section Six for detail).

Third, we select changes of near-term (i.e., 30-day) expectation in volatility, rather than swings of actual volatility, to capture the heteroskedasticity. On the one hand, the realized volatility contains no uncertainty to market participants and may deviate from the definition of risk. On the other hand, changes in the expectation reflect more information in FOMC statements than changes in actual volatility. The majority of dates for measuring volatility before and after an announcement are overlapped. Changes in the expectation of volatility take into account variations in expected returns in all days within the measuring scope. Whereas, differences in actual volatility essentially compares the return of the last day with that of the first day in the measuring range.

In practice, we identify monetary policy shocks through the varying expected volatility of the policy indicator (i.e., the volatility surprise), given its implication for fluctuations in future monetary policy shocks. This approach bears a strong theoretical connection with the risk-taking channel. We attempt to investigate whether a monetary-policy-induced variation in long-term interest rate risk perceived by financial markets affects the level of a long-term real rate and, more importantly, whether it influences financial frictions, banks' risk-taking behavior, and real economic activity. In this venue, volatility surprises stimulate monetarypolicy-induced movements of the policy indicator.

We follow the identical procedure as the aforementioned 2-stage regressions. We consider the volatility surprise identified via the event study method as the policy instrument and run the first-stage regression as follow.

$$
\text { Monthly: } u_{t}^{p}=\gamma V O L_{t}+\epsilon_{t}
$$

Then in the second stage, we estimate $\frac{s^{q}}{s^{p}}$, the reactions of $u_{t}^{q}$ relative to $u_{t}^{p}$ in response of a unit increase of monetary policy shocks. The fitted value $\hat{u}_{t}^{p}$ is the component of $u_{t}^{p}$ responding to monetary policy shocks and is driven by varying expected volatility of future monetary policy shocks in long term. The second-stage regressions in equation (14) show that unexpected variation in the volatility expectation drives contemporaneous exogenous 
movements of other endogenous variables.

$$
\text { Monthly : } u_{t}^{q}=\frac{s^{q}}{s^{p}} \hat{u_{t}^{p}}+e_{t} \text { where } \hat{u_{t}^{p}}=\gamma V O L_{t}
$$

Overall, monetary policy shocks in the risk-taking channel are identified through the second-moment movement of a representative long-term rate and the entire information content of FOMC statements. Besides, we make no redundant restrictions on other structural parameters.

\section{Data and Sample}

Our sample ranges from January 2003 to January 2018, including 140 FOMC meetings and the entire ZLB period.

In the SVAR model, we include four endogenous variables, such as the PCE chain-type price index, the industrial production, a monetary policy indicator, and a measure of financial frictions.

The PCE chain-type price index is a measure of prices of all domestic personal consumption of final goods ${ }^{8}$. The Federal Reserve emphasizes its role in measuring price inflation since it "covers a wide range of household spending"9. The industrial production is a sensitive indicator of production activities, and its data is available in monthly frequency. We follow the practice of Gertler and Karadi (2015) and retain the measure of financial frictions, the Gilchrist and Zakrajšek (2012) excess bond premium. The excess bond premium captures the difference in yields between the corporate and Treasury bonds with identical maturity after statistically purging the impact of expected corporate default risk. Empirically, it is a viable indicator of the credit market sentiment and the degree of financial frictions in financial markets.

We propose a long-term real interest rate, i.e., the 10-year Treasury inflation-protected securities (TIPS) yield, as an alternative policy indicator. Hanson and Stein (2015) and Nakamura and Steinsson (2018) suggest that TIPS yields reflect virtually all the responses of nominal interest rates on FOMC dates to monetary policy surprises. Furthermore, a TIPS yield is less susceptible to the price shock and more responsive to monetary policy actions, measured by various monetary policy surprises, than the correspondent nominal rate. Table 1 shows the contemporary changes of 10 -year real and nominal rates in response to mon-

\footnotetext{
${ }^{8} \mathrm{~A}$ detailed comparison between CPI and PCE price index is provided by McCully, C. P., et al. (2007). "Comparing the consumer price index and the personal consumption expenditures price index." Survey of Current Business 87(11): 2633.

${ }^{9}$ See official website of the Federal Reserve: https://www.federalreserve.gov/faqs/economy_14419.htm
} 
etary policy surprises and reduced form VAR residuals of non-policy variables. RES_IP and RES_PCE are the VAR residuals of industrial production and PCE price index in our baseline 4-variable VAR model with 10-year nominal or real rate being the policy indicator, respectively. The statistics illustrates that changes in the 10-year nominal rate are highly subjected to price fluctuations. Whereas, changes of the 10-year TIPS yield are more responsive to monetary policy surprises-respectively are the policy rate surprise and volatility surprise which will be introduced shortly after-and innovations in output but are relatively inactive to swings in the price level. This property of the TIPS yield helps us focus on the effect of monetary policy, rather than on the reaction to the noisy price fluctuation. We use the 10-year TIPS yield in the interest rate channel and the risk-taking channel in which long-term rates are theoretically relevant. In comparison, to investigate the credit channel, the policy indicator used in Gertler and Karadi (2015) is the one-year Treasury yield.

Table 1: The Contemporary Responds of 10-year Real or Nominal rate to Shocks

\begin{tabular}{lcc}
\hline & $(1)$ & $(2)$ \\
& $\Delta 10 Y$ TIPS & $\Delta 10 Y$ \\
\hline VOL & $0.071^{* * *}$ & 0.026 \\
& $(0.023)$ & $(0.020)$ \\
PRATE & $1.080^{* *}$ & $0.992^{* *}$ \\
& $(0.470)$ & $(0.436)$ \\
RES_PCE & 10.400 & $25.429^{* *}$ \\
& $(6.990)$ & $(11.258)$ \\
RES_IP & $-6.830^{*}$ & 2.046 \\
& $(3.850)$ & $(2.102)$ \\
\hline Observations & 177 & 177 \\
$R^{2}$ & 0.173 & 0.080 \\
\hline$* p<0.05, * * p<0.01, * * * p<0.001$ & \\
Note: HAC Robust standard errors in parentheses
\end{tabular}

We generate two event-study monetary policy surprises as the policy instruments. The first monetary policy surprise, the policy rate surprise, is directly borrowed from Kuttner (2001). It captures the changes of the spot-month federal funds future rate on the FOMC announcement dates. It is a common practice that assesses exogenous monetary policy actions in light of the Taylor rule. The only modification we make is to adjust the sample period according to ours. The other monetary policy surprise that we innovate for the risktaking channel is the volatility surprise. We generate the volatility surprise by capturing the unexpected change of near-term expectation in long-term rate volatility around each 
FOMC meeting announcement. We select the interest rate volatility of 10-year Treasury bonds in order to match with the maturity of policy indicator. The volatility surprise demonstrates monetary-policy-induced changes in the expected volatility of future monetary policy shocks in the long run perceived by financial markets. In Section Six, we provide a detailed procedure for producing the volatility surprise, including the selection of a time window and the conversion to monthly time series. Both surprises are converted into monthly time series to fit into the monthly SVAR model.

When setting the volatility surprise as the policy instrument, we are not intended to presume that the Federal Reserve attempts to control or manipulate expected volatility of an interest rate. Instead, the Federal Reserve's communication, such as communication styles, languages in the summary of economic projections and more, may contribute to the exogenous impact of monetary policy on financial markets. In the SVAR model, as unexpected by economic agents other than the Federal Reserve, the influences of communication in FOMC announcements constitute a portion of exogenous monetary policy shocks to the VAR system. These effects thus should be incorporated to identify the monetary policy shocks. The two monetary policy surprises demonstrate two distinctive and orthogonal dimensions of the impact of monetary policy announcements, such as the influence on short rates level versus the effects on long rate volatility. Another critical difference between the two monetary policy surprises is the measuring objects. The policy rate surprise lasers the focus on changes in the policy rate, while the volatility surprise comprehensively evaluates monetary policy announcements in terms of the risk implication. In the model, we stimulate monetary policy shocks with the policy rate surprise in the credit channel and the interest rate channel. Both channels are characterized by a Taylor rule type of monetary policy reaction function. On the contrary, the risk-taking channel accepts a broader definition of monetary policy. Therefore, the volatility surprise is ideal for initiating the monetary policy shocks in the risk-taking channel in order to investigate the risk-side monetary policy transmission.

\subsection{First-stage Regression and the Relevance of External Instruments}

A common issue of the estimations with instrumental variables is the weak instrument. Specifically, if the covariance between an endogenous regressor and its instrumental variable is low, the IV estimator is severely biased toward the OLS estimator. In this case, the instrumental variable is considered as a weak instrument. We adopt Stock and Yogo (2005) criteria (a larger than 10 F-statistics) to determine the relevance of instrumental variables. In various settings, the policy indicator is either the one-year Treasury yield or 10-year TIPS yield. And the policy instrument is either the volatility surprise or policy rate surprise. In 
the first-stage regression, we regress the reduced form VAR residual of either policy indicator on each monetary policy surprise. Table 6 shows the results. The F-statistics is based on heteroskedasticity and autocorrelation consistent (HAC) standard deviation.

Table 2: The Results of the First-stage Regression

\begin{tabular}{lcccc}
\hline & $\begin{array}{c}\text { Risk-taking } \\
\text { 10Y TIPS(1) }\end{array}$ & $\begin{array}{c}\text { Interest Rate } \\
\text { 10Y TIPS(1) }\end{array}$ & Credit & $1 \mathrm{Y}$ \\
\hline VOL & $0.058^{* * *}$ & & & 0.033 \\
& $(0.012)$ & & & \\
PRATE & & $0.983^{* * *}$ & $0.016)$ \\
& & $(0.271)$ & $(0.146)$ & \\
\hline Obs. & 178 & 178 & 178 & 178 \\
Robust F-Stat. & 23.96 & 13.12 & 30.17 & 4.17 \\
\hline
\end{tabular}

Note: ${ }^{*} p<0.05,{ }^{* *} p<0.01,{ }^{* * *} p<0.001$. Robust standard errors in parentheses. The dependent variable is the reduced form VAR residual of the policy indicator specified in the second row. VOL and PRATE are the volatility surprise and policy rate surprise converted into monthly time series.

In the models which use the one-year Treasury yield as the policy indicator, the coefficient of policy rate surprise is significant at a high multitude. This indicates that unexpected policy rate changes are a strong instrumental variable for the monetary policy projected on short-term rates. In contrast, volatility surprises are barely relevant with shifts in short-term rates. Overall, reaction of the one-year yield to monetary policy surprises is instantaneous.

When considering the 10-year real rate as the policy indicator, the volatility surprise and policy rate surprise are both strong instruments with higher than 10 F-statistics. However, the strong relevance is significant between the lagged VAR residual of 10-year TIPS yield and the two monetary policy surprises. It may be because these monetary policy surprises have a more persistent impact on long-term real rate than what they do on short-term rates. This lagged matching can also be attributed to the conversion of monetary policy surprises from daily to monthly time series, a process in which unavoidably extend the persistence of surprises. Matching the lagged residual of policy indicator with current monetary policy surprises may shorten the time interval between monetary policy actions and reactions of financial markets.

Concern about the non-contemporaneous matching is that historical values of the policy indicator seem predictive for volatility surprises. Thus, identified monetary policy shocks might reflect a systematic component of monetary policy. However, we find no evidence to 
bolster this argument in the daily date analysis and Granger causality test (please refer to Appendix B).

We also report that the volatility surprise is more significant as an instrumental variable for the long-term real rate than the policy rate surprise is. The explanation power is higher as well. This evidence suggests the difficulty of merely applying the policy rate or short-term rates to explain the more volatile fluctuations in long-term rates.

In summary, we construct a 4-variable SVAR model with a financial variable indicating financial frictions. Departing from the stylized short-term rates, we adopt a long-term real rate to indicate the monetary policy impact to the whole yield curve. To properly identify the monetary policy shocks, we generate a new high-frequency, event-study measure of perceived risk in long-term rate. As a result, we take the risk-side impact of FOMC statements on long-term rates into the account of the measurement of monetary policy. To be comparable with the literature, we retain the policy rate surprise to denote the monetary policy stance consistent with the Taylor rule. In the next section, we correspond the first three significant combinations of policy instruments and indicators with three mainstream monetary policy transmission channels and evaluate their effectiveness in transmitting to the economy.

\section{Empirical Results}

\subsection{Review of the Credit Channel}

At the beginning of this section, I review the empirical results in Gertler and Karadi (2015) since their work lays the econometric foundation for this paper and evaluates the validity of the credit channel. They propose the SVAR model with identification through external instrument for the study of monetary policy transmission. They follow the convention in the monetary transmission literature and make two assumptions. First, monetary policy only directly affects the short end of the yield curve. Second, monetary policy is measured by the federal funds rate or its close alternatives, like Eurodollar rates. In practice, they use 1-year Treasury yield as the policy indicator to reflect current policy rate changes and forward guidance. To capture the exogenous monetary policy actions, they use the policy rate surprise as the policy instrument.

Their result illustrates that a change in short-term market rate motivated by a shift in policy rate drives fluctuations of the excess bond premium and, in turn, the lagged movements of output. They argue that a frictional financial market is crucial to the propagation of monetary policy, corresponding to the central role of external financing premium in the credit channel proposed by Bernanke and Gertler (1995). In the credit channel, a contractionary 
change of policy rate, as claimed by Bernanke and Gertler (1995), both affect borrowers' balance sheet quality and lenders' capital availability. The variation in both avenues eventually influences the spread between the costs of external and internal financing. Bernanke et al. (1999) further develop this channel into a financial accelerator mechanism by incorporating general equilibrium modeling and contract theories in a business cycle framework. The impulse responses of the excess bond premium and output support the effective transmission through the credit channel. In short, the theoretical and empirical work leads to the same argument that the policy rate change propagates to the economy through, though may not exclusively through, a financial accelerator mechanism.

The unsolved question for this model is whether long-term interest rates play a role in

the transmission. Exhaustively, there are three hypotheses given the validity of Gertler and Karadi (2015) finding. First, monetary policy only affects short-term rates, and longterm rates are unresponsive. Second, monetary policy only influences movements of shortterm rates which in turn drives sways of long-term rates. Third, monetary policy affects short- and long-term rates individually in different mechanisms. The abundant empirical evidence of the significant impact of monetary policy on long-term rates rejects the first hypothesis (Gürkaynak et al. (2005), Wright (2012), Hanson and Stein (2015)). However, no empirical proof has been found for the second and third hypotheses from the monetary policy transmission perspective. We test them by introducing a long-term real rate as the policy indicator into our VAR model. Furthermore, if any of the two latter hypotheses are true, we test whether they are blind alleys in transmission. In other words, we monitor whether the impact of monetary policy on the yield curve can eventually influence economic aggregates.

\subsection{Testing the Interest Rate Channel: Long-term Real Rate as a New Policy Indicator}

The Keynesian interest rate channel, corresponding to the aforementioned second hypothesis, is almost the textbook view of the monetary policy transmission mechanism in which longterm rates play a role. It may be partitioned into two steps, such as the transmission to the yield curve and that to the economy. The former, in general, characterizes three suppositions. First, the monetary policy is measured by changes in the policy rate. Second, changes in short-term rates pass through to long-term rates. Third, nominal and real rates move synchronously due to the sticky price setting in Keynesian-type models. Statistically, we test the validity of those three hypotheses jointly by observing whether policy rate surprises can stimulate fluctuations in a long-term real rate.

In terms of the second proposition, the literature mentions two avenues regarding transmission from short to long rates. On the one hand, a shift in the short rate leads the market 
to adjust the expected path of future short rates according to the expectations hypothesis of term structure. On the other hand, more recent researches, e.g., Hanson and Stein (2015), indicate that unexpected changes in the policy rate affect term premia on distant forward rates. Since we focus on attesting whether the pass-through from short to long rates is effective, we integrate the effects in both avenues.

In terms of the transmission to economic activity, the interest rate channel assumes a cost-of-capital effect typically discussed in the neoclassical theory of investment. Accordingly, changes in the cost of capital affect real activities through their impact on spendings on durable goods and fixed investment.

To examine the monetary transmission in the interest rate channel, we consider the 10-year TIPS yield as the policy indicator, and adopt the policy rate surprise to identify monetary policy shocks.

In the first stage regression, if the transmission to the yield curve is valid, the coefficient in the first stage regression should be positive and statistically significant. It is confirmed by our results in Table 2. Furthermore, the F-statistics is significantly higher than 10. In the second stage, we estimate the mapping vector between monetary policy shocks and reduced form residuals of endogenous variables under the restriction that monetary policy affects long-term rates primarily through variation in the policy rate.

Figure 2 shows impulse responses of endogenous variables to "monetary policy shocks identified in the interest rate channel". In comparison, we also show the impulse responses from the conventional Cholesky identification scheme in the right column. Both columns show impulse responses to a one standard deviation structural monetary policy shock. In the right column, the impulse responses in the VAR model with the conventional Cholesky identification are insignificant for all variables. In the left column, monetary policy shocks are identified as the systematic movements of a long-term real rate in responses to unexpected policy rate changes on FOMC announcement dates. Influenced by a contractionary policy shock, the price level gradually slides for roughly eight months and remains at a low level for an extended period. The reaction of output is silent to this shock. The confidence band is wide. The muted response in production provides opposing evidence to the cost-of-capital effect in the neoclassical theory of investment and implies the failure in transmitting to the economy in the interest rate channel. Furthermore, the typically countercyclical excess bond premium behaves abnormally. It declines right after a tightening policy shock but quickly recovers to zero. It may be interpreted by a lagged pass-through from the cost of capital to lending rates. Banks may take in the long-term rate spike, leading to an instantaneous reduction of the excess bond premium. Within a quarter, banks seem eventually pass through 

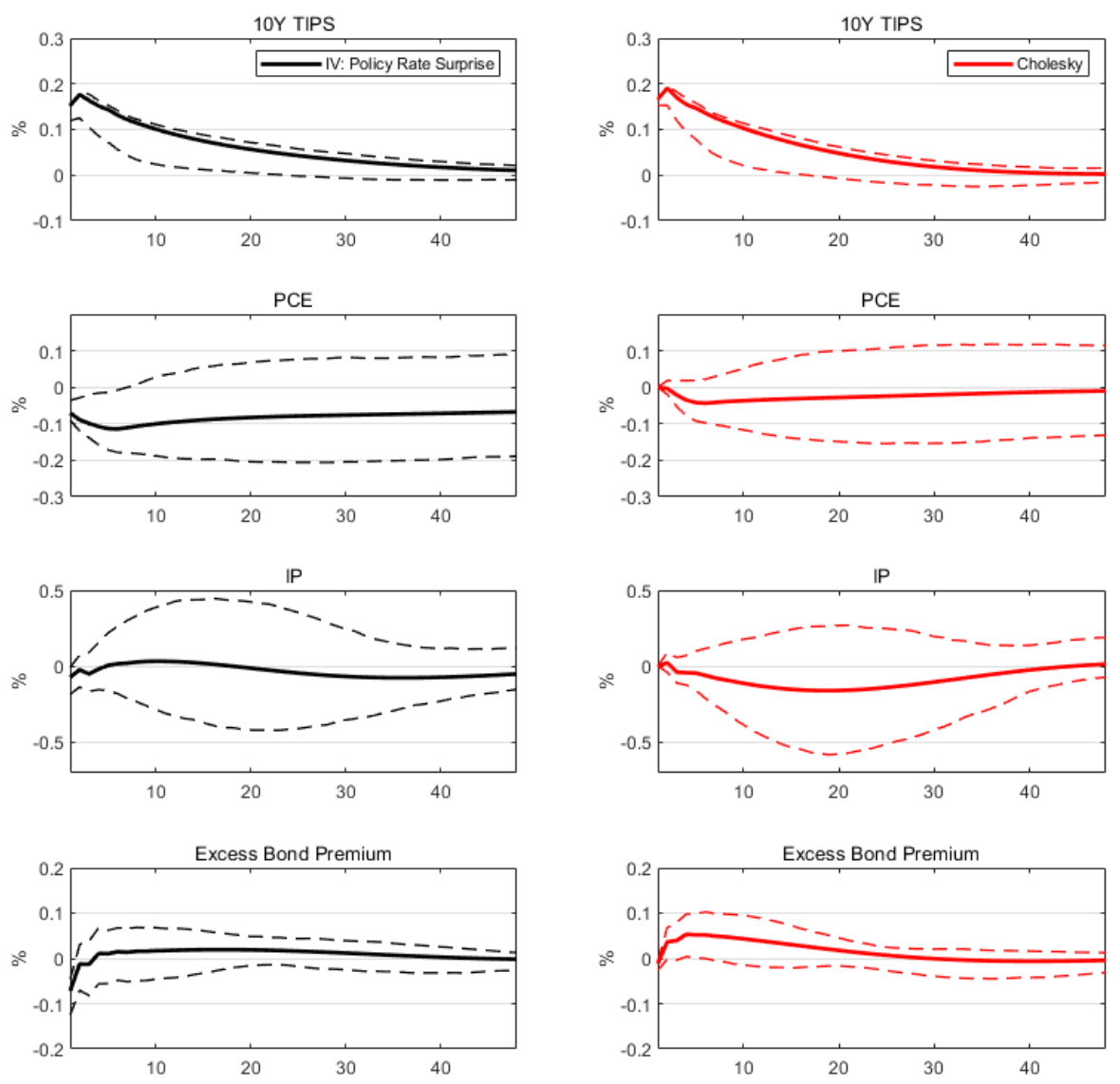

Figure 2: The impulse responses to the monetary policy shocks identified in the interest rate channel

the exogenous increase of cost of capital to borrowers and thus the excess bond premium return to a flat response.

\subsection{The Risk-taking Channel: the Volatility Surprise as the New Instrument}

Risk is a critical factor for asset pricing in finance studies, but it is less explored at the aggregate level, especially in the studies of monetary policy (related work includes Bekaert et al. (2013), Baker et al. (2016), Husted et al. (2017)). Borio and Zhu (2012) first proposed the risk-taking channel in monetary policy transmission. Specifically, the monetary policy may affect risk perceptions or risk tolerance of financial intermediaries and then have a first-order impact on economic activity. Empirically, this paper is the first attempt to find an appropriate measure that specifically accounts for influences of monetary policy on 
aggregate risk perception, especially the risk attitude in the bond market where monetary policy primarily exert impact on.

We use the 10-year TIPS yield to indicate the monetary policy actions and the volatility surprise to instrument the identification of monetary policy shocks. Importantly, the volatility surprise incorporates the impact of all the components of monetary policy, notably including effects of unconventional monetary policy tools. Monetary policy shocks in the risk-taking channel are identified as variation in a long-term real rate driven by monetarypolicy-induced changes in perceived fluctuations of monetary policy shocks in the long run. For instance, if financial markets expect less volatility of monetary policy shocks in the future ten years due to an FOMC announcement, we consider this monetary policy as expansionary.
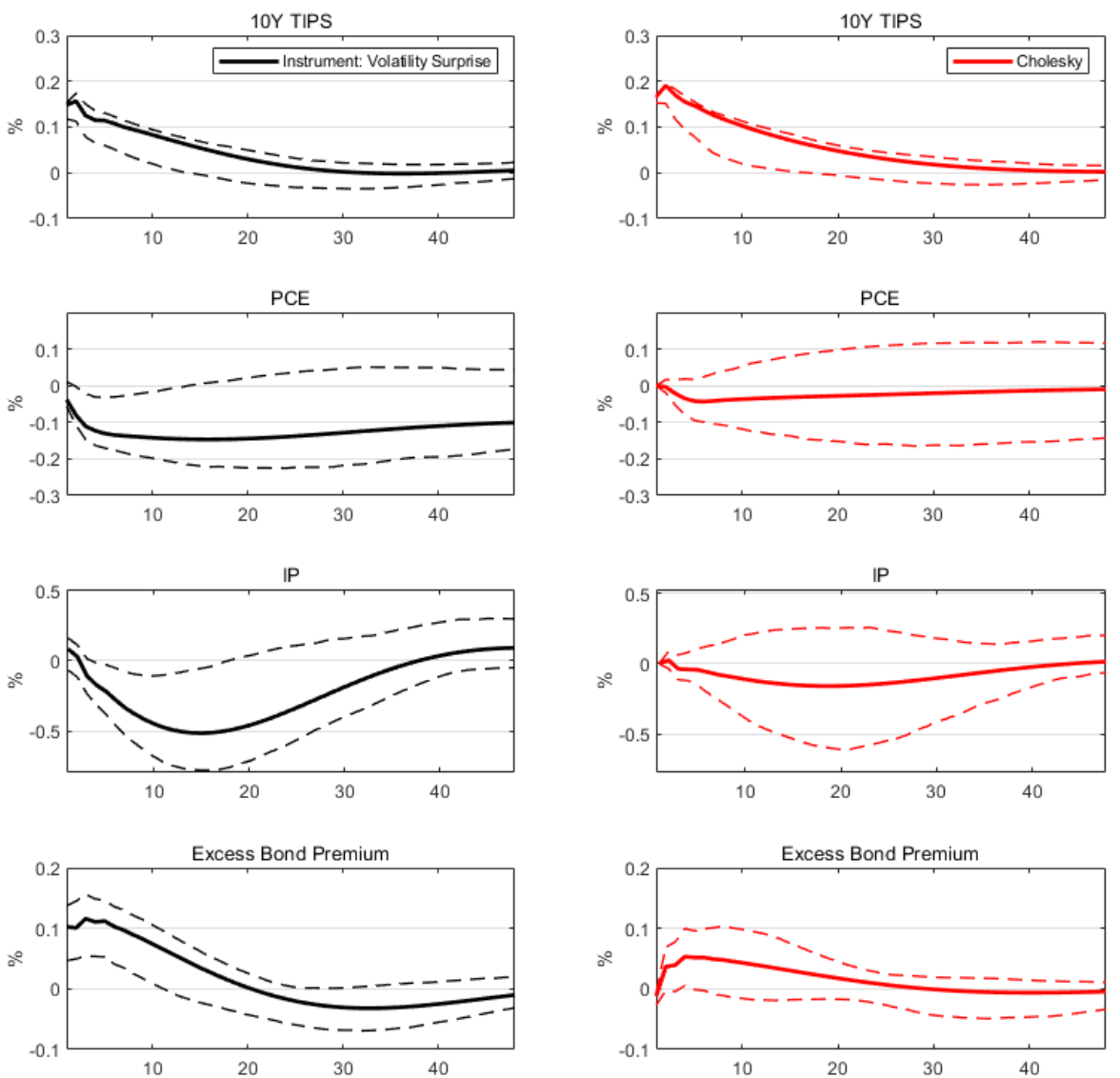

Figure 3: The impulse responses to monetary policy shocks identified in risk-taking channel

The Figure 3 shows the impulse responses to monetary policy shocks identified in the risk-taking channel. A one-standard-deviation contractionary monetary policy shock leads 
to a significant and persistent drop in price level, a similar result as the "interest rate channel" model. What interests us is the strong hump-shape reactions of the excess bond premium and output. Under a tightening shock transmitting through perceived risk, the credit environment immediately aggravates, and excess credit costs hike up for ten basis point for approximately a year. The same shock also leads to 50 basis point decline in output. Additionally, we observe close interaction between financial frictions and industrial production. The trough of production coincides with the time point when the response of excess bond premium is indistinguishable from zero.

Our results suggest the viability of the risk-taking channel. FOMC statements somehow influence the expected volatility of future monetary policy shocks in the long run. This aspect of monetary policy shows strong implication for long-term real rates, financial frictions, and real activity.

\section{Discussion}

\subsection{Credit and Interest Rate Channels: Financial Accelerator or Cost-of-Captial Effect}

We compare our results in the interest rate channel model with those in Gertler and Karadi (2015), whose distinction from ours centers on the selection of policy indicators. They select one-year Treasury yield as the policy indicator and generate sensible impulse responses of the excess bond premium and output to monetary policy shocks. When using 10-year real yield as the policy indicator, those responses are muted.

The multidimensionality of the monetary policy may contribute to the distinctive impulse responses. Monetary policy consists of the headline figure and the FOMC statement. The headline figure in most cases is the policy rate target and is communicated with the public by an unambiguous, narrow target range of the federal funds rate. It may dominate the impact of monetary policy on short rates, but it could be reluctant to represent the whole influence on longer-term rates. Meanwhile, an FOMC announcement incorporates more diversified information, such as the FOMC's Summary of Economic Projections (SEP), forward guidance, LSAPs, and other details of open market operations. Those information contents and associated operations influence short rates as well as long rates. Since those new policies affect the slope of the term structure of interest rates, Eberly et al. (2019) refer to those new elements in the current monetary policy framework as slope policies. Slope policies are thus differentiated from the traditional level policy that sets the current level of the Federal funds rate. For instance, Gagnon et al. (2011), Rosa (2012), Swanson (2015) and others indicate that LSAPs have much greater influence to long-term Treasury yields than to short-term yields. 
Gertler and Karadi (2015) identify the impact of policy rate changes on a short-term rate as the exogenous (monetary policy) shocks and focus on the transmission via shortterm rates. It is a proper identification scheme since adjustments in Reserve's operations on short-term rates. Whereas, the policy impacts on long-term rates are unrevealed in the black box of transmission. Their results may suggest that effects of unexpected policy rate hikes on the short end of the yield curve are adequate to result in credit crunch and shrinkage of production. But this model has no access to whether, and how, a long-term interest rate plays a role in this transmission.

When considering long-term rates as a node of monetary policy transmission, their linkage with policy rate changes seems marginally drive economic activity. We delve into the literature in search of theoretical or institutional clues for the muted responses of the excess bond premium and output in the interest rate channel model.

The unresponsiveness of the excess bond premium may attribute to two explanations. Financial intermediaries may passively adjust their expectation in future short-term rates and their baseline long-term lending rates when encountering exogenous policy rate changes. Hence, an increase in the cost of capital due to a policy rate change may pass through to borrowers. In a competitive market, a bank may not have an incentive to augment excess credit premium on baseline long-term rates as long as the information of the expected path of future short rates is publicly available in financial markets. In fact, the Federal Reserve periodically releases the estimated expected yield and term premium data of Treasury bonds with a full spectrum of maturities based on approaches in Kim and Wright (2005) and Adrian et al. (2013). This information offers limited arbitrage space for a bank to implement a heterogeneous premium on baseline rates. Another explanation is a story of yield-searching investor proposed by Hanson and Stein (2015), among others. This story aims to justify why unexpected policy rate changes are highly associated with significant changes in term premia on distant real forward rates. This short-lived variation in term premia due to demand shocks in the bond market is well observed not only by empirical research, but also in the institutional behaviors of commercial banks (Stein (1989)). Responses of the excess bond premium may confirm that these demand shocks in financial securities trading are too trivial and transitory to affect banks' lending decisions. In combine, the muted reaction of the excess bond premium may be justified from the perspectives of interest rate pass-through and short-lived drifts in term premia. However, our results may be too preliminary for us to make a preference in those explanations.

Contradicting to the cost of capital effect in the neoclassical theory of investment, our evidence shows that fluctuations in a long-term real rate induced by policy rate changes do not lead to variation in output. This finding is consistent with Blinder and Maccini 
(1991), Chirinko (1993), among others, which find the difficulty in identifying a quantitatively significant effect of the neoclassical cost-of-capital variable in "interest-rate sensitive" components of aggregate spending. Whereas, due to the multidimensionality of monetary policy, it should be premature to conclude that monetary policy fails to transmit to the economy.

Additionally, the quiet response of output in the interest rate channel reconfirms the necessity to not only consider policy rate movements, but also investigate the entire information content of FOMC statements. The FOMC statements may include some components of monetary policy other than the policy rate targeting that influence both long-term rates and economic activity. Thus, by identifying the risk-taking channel via the volatility surprise, we suggest a more comprehensive identification strategy of monetary policy shocks.

Another noteworthy observation is that the responses of excess bond premium and output are synchronized. In fact, it is the case for all three channels. For example, in Gertler and Karadi (2015) model, a hike of excess credit costs accompanies a decline in output. In the interest rate channel model, the unchanged excess bond premium is followed by a flat response of production. It seems that the financial frictions, rather than the cost of capital, are a critical driving factor of economic activity. This finding strongly supports financial accelerator models first proposed by Bernanke et al. (1999). They feature amplifier effects of credit market frictions on monetary policy transmission. Their claim is in accordance with our results. The hike of excess credit costs demonstrates the aggravation in information asymmetry and the increase of agency costs in the credit generating process, leading to widespread real effects. Meanwhile, our evidence opposes the Modigliani and Miller (1958) Theorem, which implies that financial structure is irrelevant to real economic outcomes.

Consequently, flat impulse responses of financial frictions and output to policy shocks in the interest rate channel lead us to explore the content of monetary policy beyond policy rate changes.

\subsection{Interest Rate and Risk-taking Channels: A More Comprehensive Identification Strategy}

We notice that systematic changes of a long-term rate responding to policy rate decisions do not trigger sways of the excess bond premium and output. Whereas, changes in the long-term real rate caused by shifts in perceived interest rate risk does.

Campbell et al. (2012) and Nakamura and Steinsson (2018) demonstrate that market participants may update their expectations about economic fundamentals in response to Federal Reserve's announcements. The Federal Reserve also signal information about the state of the economy to the public (Romer and Romer, 2000; Melosi, 2016). These effects 
may be sourced from the private information held by the Federal Reserve and exogenous to financial markets. In order to evaluate the exogenous impact of entire information content in FOMC announcements, we do not specially tease out these effects in the volatility surprise and instead incorporate them in the monetary policy shock identification. Therefore, facing a policy shock stimulated by a volatility surprise, financial intermediaries' update of economic prospects may influence their perception in future monetary policy actions. Thus lead to variation in the excess bond premium.

Furthermore, we conjecture that monetary policy may have a more significant impact on the supply of long-term capital than the demand. The cost-of-capital effect focuses on the demand side in credit markets. For firms' long-term investment decisions, fluctuations in the cost of capital may be too transitory to be considered. Moreover, capital adjustment costs may take an additional toll on firms' frequently adjustment of capital stocks if they adopt a cost-oriented investment strategy. As a result, firms may not be cost-efficient in closely tracking borrowing costs and adjusting long-term investments accordingly. The investigation of the risk-taking channel provides us with crucial insight into the supply side of long-term capital. Financial intermediaries may be aware of variation in the volatility of monetary policy shocks. An unexpected soar of the volatility may indicate the increasing difficulty in interest rate forecasting and the additional provision for potential interest losses. These real costs may render banks with incentives to add an excess premium on baseline lending rates and shrink risk-taking behavior. Our results demand further exploration and theoretical explanation in the real impact of second-moment movements in interest rates.

Another noteworthy finding is that, in both models, the price is well behaved without demonstrating the price puzzle. This result suggests that movements in the price level bear closer relationship with changes in interest rates than with the particular policy tools driving those interest rate changes. In both models, it seems that innovation in long-term real rate stimulates variation in the price, regardless of the components of monetary policy that trigger this innovation. Comparing with the price responses in the Gertler and Karadi (2015) "credit channel" model, the price level responds more rapidly to innovations in long-term rates than those in short-term rates. It takes approximately two years for the price to distinguishably react to the policy shocks identified in the movement of short-term rate. In contrast, it takes much less time for the price responding to shocks identified in the long rate. This finding has two implications. From one perspective, it seems that the policy transmission from shortto long-term rates is not as instant as suggested by the expectations hypothesis. Otherwise, the price should behave the same in two models without the difference in lagged effects. From another aspect, our results may demonstrate a conflict for the Fed using a short-term interest rate to target the long-run inflation. Inflation targeting denotes that monetary policy 
is conducted with a long-run target of inflation (detailed discussed by Svensson (1999a,b)). Supposed a monetary authority adopt a short-term rate, such as the funds rate, as the main instrument for inflation targeting but inflation is more responsive to changes in long-term rates, then the effectiveness of monetary policy may be discounted.

\subsection{Credit and Risk-taking Channels: All Roads Lead to Rome}

Monetary policy shocks identified in the credit channel and the risk-taking channel both invoke the hump-shape reactions of the excess bond premium and output. However, the transmission mechanisms are different. The credit channel identifies the monetary policy shocks as variation in a short-term rate caused by unexpected policy rate changes. In contrast, the risk-taking channel defines monetary policy shocks as movements in a longterm real rate induced by the FOMC-statement-driven changes in risk perceived for longterm interest rates.

One critical question here is how the transmissions of monetary policy through the two ends of the yield curve relate to each other. If they are relatively independent of each other, it would be appropriate to adopt different mechanisms for stimulating policy-induced movements in short- and long-term rates. Otherwise, policy rate changes may be sufficient to measure monetary policy in all transmission channels, supporting a policy reaction function akin to Taylor rules. We run the following regression to investigate whether a policy rate surprise can explain the contemporaneous volatility surprise. Thus, we may infer whether the impact of monetary policy on short- and long-term rates are interrelated.

$$
\operatorname{VOL}_{t}=\alpha+\beta \operatorname{Prate}_{t}^{-}+\gamma \operatorname{Prate}_{t}^{+}+\epsilon_{t}
$$

We use monthly time series rather than the event study time series, which are only consisted of FOMC events, to include all the data points on the time axis, and avoid the data selection bias. It is necessary because the intervals between any two FOMC meetings are irregular, especially when some unscheduled meetings are taken into account. $V O L_{t}$ is the monthly volatility surprise and Prate $_{t}$ is the monthly policy rate surprise. Prate ${ }_{t}^{-}$ records unexpected policy rate drops and notes zero for FOMC meetings with sudden policy rate hikes. As the opposite case, Prate $t_{t}^{+}$records unexpected positive changes of the policy rate and takes zero when an opposite change incurs. As to the endogeneity issue, we assume a unidirectional causality from a policy rate surprise to the contemporaneous volatility surprise. This design is because an FOMC announcement takes precedence over the reaction of the financial market. The monetary authority must wait until the next FOMC meeting to change the policy rate target in order to address the current period volatility surprise. 
Table 3 shows a non-linear relationship between a policy rate surprise and a volatility surprise. An unexpected policy rate cut is associated with a negative volatility surprise, indicating that an expansionary policy rate change is likely to be effective in reducing the perceived risk in long-term interest rates. On the contrary, an unexpected increase in the policy rate is uncorrelated with volatility surprises. This asymmetric relationship alone is worthwhile for further exploration. It may be associated with the insurance effect of monetary policy. If the primary goal of monetary policy is to cope with the downside economic risk, an expansionary monetary policy may curtails the public's negative economic outlook more than an identical-magnitude contractionary policy would aggravate the pessimistic prospect (Borio and Zhu, 2012). Overall, the impact of a policy rate movement on its corresponding volatility surprise is trivial since the $\mathrm{R}$ squared is less than 0.03. Furthermore, policy rate changes are far from being a determinant of volatility surprises as the F-statistics (2.64) is much less than the criteria of 10 .

Table 3: The Explanatory Power of a Policy Rate Surprise on a contemporaneous Volatility Surprise

\begin{tabular}{lc}
\hline & VOL \\
\hline $\mathrm{C}$ & 0.010 \\
& $(0.029)$ \\
NEG_PRATE & $2.341^{* * *}$ \\
& $(0.843)$ \\
POS_PRATE & 0.155 \\
& $(3.320)$ \\
\hline Observations & 188 \\
$R^{2}$ & 0.029 \\
\hline$* p<0.05, * * p<0.01, * * *$ & $p<0.001$ \\
Note: HAC Robust standard errors in parentheses
\end{tabular}

The low explanatory power of policy rate surprises on volatility surprises suggests the weak connection between monetary policy transmission mechanisms through the short and long ends of the yield curve to the economy.

In brief, we notice that monetary policy affects short-term rates through operations and guidance on the policy rate, while influences long-term rates via altering the perceived risk of long-term interest rates. Both channels induce variation in financial frictions and, in turn, lagged adjustments of output. At last, the systematic component of long-term rates in response to policy rate changes is significant but does not contribute to the dynamics of economic activity. 


\section{Construction of the Volatility Surprise}

The generating procedure of the volatility surprise is crucial to our identification of the monetary policy shocks in the risk-taking channel. However, technical details of the process may divert readers from our empirical results in monetary policy transmission. Thus, after presenting our findings, we set up the following section to discuss our practice in the event study of the risk-side impact of monetary policy in high-frequency data.

\subsection{Event Study of Monetary Policy Impact on Interest Rate Volatility}

The methodology of generating the volatility surprise should be consistent with the theoretical model in the risk-taking channel. The risk-taking channel implies three required properties for the volatility surprise that are associated with the exogeneity and relevance conditions for policy instruments. First is exogeneity. It should be exogenous from the perspective of financial markets which have no access to the private information set of the Federal Reserve. Thus, the volatility surprise may not be obtained from the Federal Reserve; instead, it could be collected through massive data in financial markets. Second is inclusiveness. It may reflect the integrated risk-side impact of entire information content in FOMC statements, instead of merely concerning influences of policy rate changes. The third is relevance. It should bear a close relationship with interest rate/ bond markets since monetary policy primarily intends to affect these markets. In short, the goal is to identify the impact of the entire information content in FOMC announcements on the interest rate risk perceived by bond markets.

Our event study approach stems from Kuttner (2001). He applies a 30-minute or one-day time window around each FOMC announcement on near-term federal funds rate futures to capture exogenous monetary policy actions. This method is widely employed for studying the effects of discrete events or news releases, such as Gürkaynak et al. (2005), Campbell et al. (2012) and more. In general, the event-study approach captures market price changes of financial assets and their derivatives, like futures and options, within a small time window around FOMC meetings to quantify the influence of information content of FOMC announcements.

Event study methods fit in our purpose in three aspects. First, it considers an FOMC announcement as a whole and enable us to evaluate the impact of various tools or components of monetary policy within one measure like policy rate changes or variation in interest rate volatility. Whereas, this convenience also constitutes a challenge to the identification of monetary policy shocks. It is essential to impose structural assumption on why an event study time series captures, entire or a dimension of, monetary policy. Second, it incurs no 
model uncertainty, as it is not nested to an economic model. Third, it is compatible with the irregularity of FOMC meeting dates. In each year, FOMC meetings are not held on the same dates. With the event study applied on high frequency (daily) data, we accurately match the timing of each monetary policy announcement with its correspondent second-moment movement of the interest rate.

The main differences between the event study constructed for the volatility surprise and Kuttner (2001) approach are that we consider the expected volatility of a long rate as the event study object, and that we utilize a wider (i.e. 4-day) time window to capture exogenous movements.

\subsection{The Implied Volatility of 10-year Teasury}

We extract the risk of long-term interest rates perceived by bond markets from the daily time series of 30-day option-implied volatility of 10-year Treasury-Note future price (short for "TYVIX index") obtained from Cboe Options Exchange (Cboe). The TYVIX index measures the annualized expectation in the 30-day standard deviation of the 10-year T-note 30-day futures price implied by market-traded futures and options prices. It is calculated via Black-Sholes options pricing model by assuming no arbitrary opportunities in options markets. The TYVIX index indicates the implied volatility of the 10-year Treasury yield as Treasury bond prices are inversely mapped to Treasury yields ceteris paribus.

Given the TYVIX index is denoted as a percentage of the futures price, it is influenced by changes in the futures price of 10-year Treasury note. To make a sensible comparison of the volatility at different time points, we multiply the TYVIX index with the spot-month futures price of 10-year T-note. Thus denote the TYVIX index in basis points of spot-month 10-year T-note futures price (Swanson, 2006). As a result, the varying T-note futures price level does not affect our measure.

Given that the 10-year Treasury yield is the representative long-term interest rate received most extensive attention in financial markets, we set it as the long-term rate, following the practice of Wright (2012), Hanson and Stein (2015) and others. We select implied volatility of the 10-year nominal rate to represent our measure of the volatility of long-term rates primarily with an intention to match the maturity of the policy indicator of our choice ${ }^{10}$.

Figure 4 shows the TYVIX in basis point. It soars to a peak during the onset of the financial crisis and experiences a gradual decline during the ZLB period. There are some

\footnotetext{
${ }^{10}$ Merrill Lynch provides an options volatility estimate index, the MOVE index. It is the yield curve weighted index of the 30-day options-implied volatility of 2-, 5-, 10- and 30-year bond prices. We adopt TYVIX index instead because it only measures fluctuations in the 10-year Treasury bond market and enable us to focus on the role of long-term rates in monetary transmission.
} 


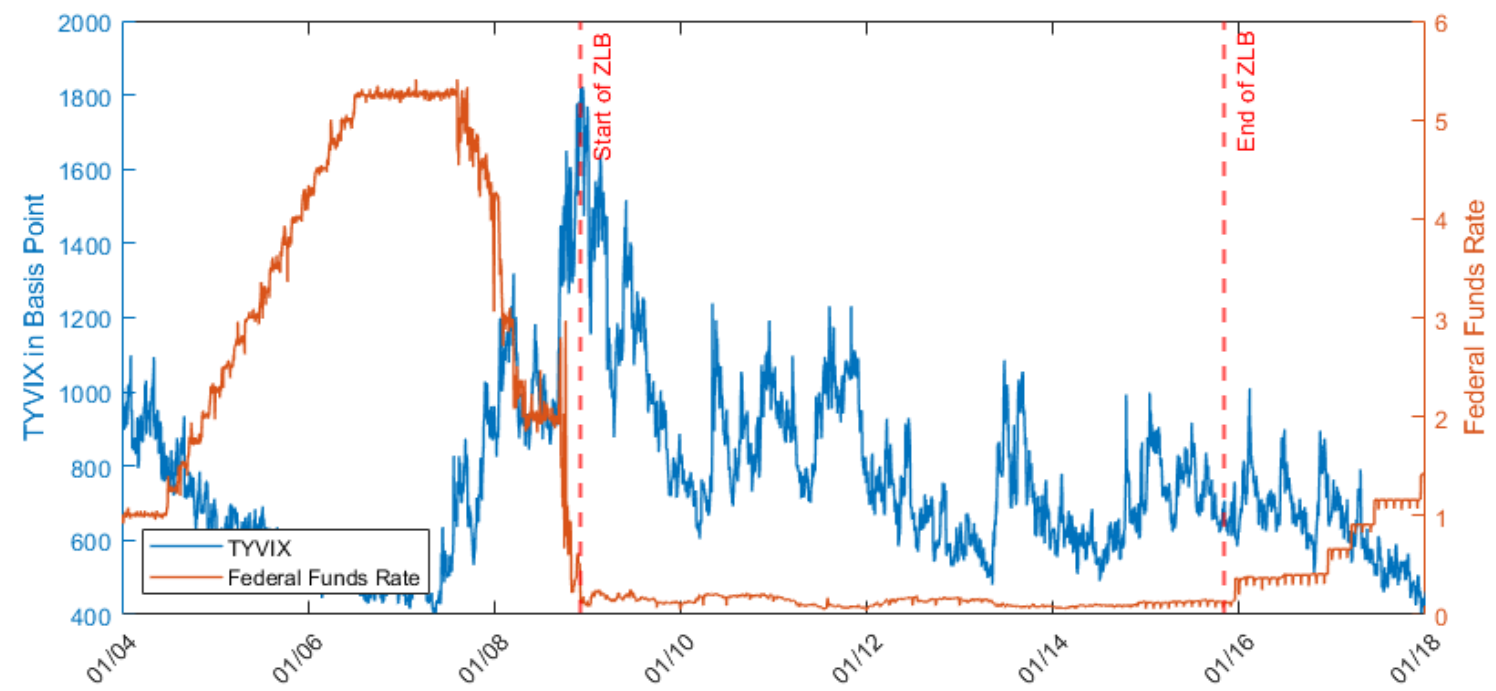

Figure 4: The Option-implied 30-day Volatility of 10-year T-note Future (Basis Point)

turbulences in the aftermath of the period. Notably, the two peaks of TYVIX index are respectively coincided with two local troughs of the federal funds rate in August 2003 and at the outset of the ZLB period in December 2008. This phenomenon indicates the cease of expansionary monetary policy paths may stimulate the implied volatility of long-term interest rate.

The 30-day measuring horizon of the TYVIX index facilitates the event study on FOMC announcements. We seek to isolate the impact of each monetary policy announcement from the influence of the policy announcement in the ensuing meeting ${ }^{11}$. A too wide measuring horizon makes the impact of several FOMC meetings overlapped in one volatility surprise. The 30-day measuring window on TYVIX index pragmatically enables the isolation for most FOMC meetings.

The FOMC of the Federal Reserve holds eight scheduled meetings per year and publicly announces new actions from deliberation at the end of each meeting. Time intervals between any two contiguous scheduled FOMC meetings range from one to two months. We select the 30-day length for calculating the volatility so that the effect of one event is shielded from being polluted by the expectation of monetary policy in the next FOMC announcement, which is more than 30-day apart. This property enables us to focus on the undergoing FOMC announcement and capture its impact independently.

\footnotetext{
${ }^{11}$ Some monetary policy tools may have extended implications on future policy decisions, such as forward guidance. We evaluate this forward-looking impact through investigating movements in a long-term rate and its volatility, rather than extending the measuring horizon of the volatility.
} 
An exception of this separation is for unscheduled FOMC meetings. The FOMC "may also hold unscheduled meetings as necessary to review economic and financial developments"12. In our sample, 20 out of 140 FOMC meetings were unscheduled. Admittedly, intervals between some scheduled and unscheduled meetings are shorter than 30 days. However, they may not seriously detriment to the isolation aforementioned. On the one hand, as those meetings are unscheduled, the scheduled FOMC meetings preceding them shall not expect them ex-ante. Thus, an unscheduled FOMC meeting may not pollute the volatility surprise generated in its preceding scheduled meeting. On the other hand, an unscheduled meeting aims to "review" the announced monetary policy in its precedent scheduled meeting and does not officially provide forward-looking information such as summary of economic projections and forward guidance. We attribute changes of the TYVIX index around an unscheduled meeting to its newly announced statement, rather than to changes in the expectation of future monetary policy actions in an ensuing FOMC meeting less than 30 days apart.

In all, the 30-day measuring horizon, to the maximum extent, enables us to focus on the impact of one FOMC statement in each volatility surprise.

\subsection{The 4-day Time Window}

The state-of-art identification assumption for event studies is that variation in a target financial variable within an adequately narrow time window around each FOMC announcement may not be contaminated by noisy economic news. Therefore, it is solely attributed to the exogenous impact of monetary policy. However, we depart from this popular Kuttner (2001) approach and consider a 4-day time window instead to control for the pre-FOMCannouncement drift in volatility. Specifically, we notice a prominent pre-FOMC-event drift of the TYVIX index in basis points, which mainly due to the short-term trading activities before each FOMC event, rather than due to monetary policy actions ${ }^{13}$. We find that this drift introduces more noise to the measurement than the inclusion of economic news in a relatively wide window. The 4-day time window is a feasible way to preclude this volatility drift.

\footnotetext{
${ }^{12}$ Cited from the website of Board of Governors of the Federal Reserve System. https://www.federalreserve.gov/faqs/about_12844.htm

${ }^{13}$ Lucca and Moench (2015) first introduce this concept for financial assets yields.
} 


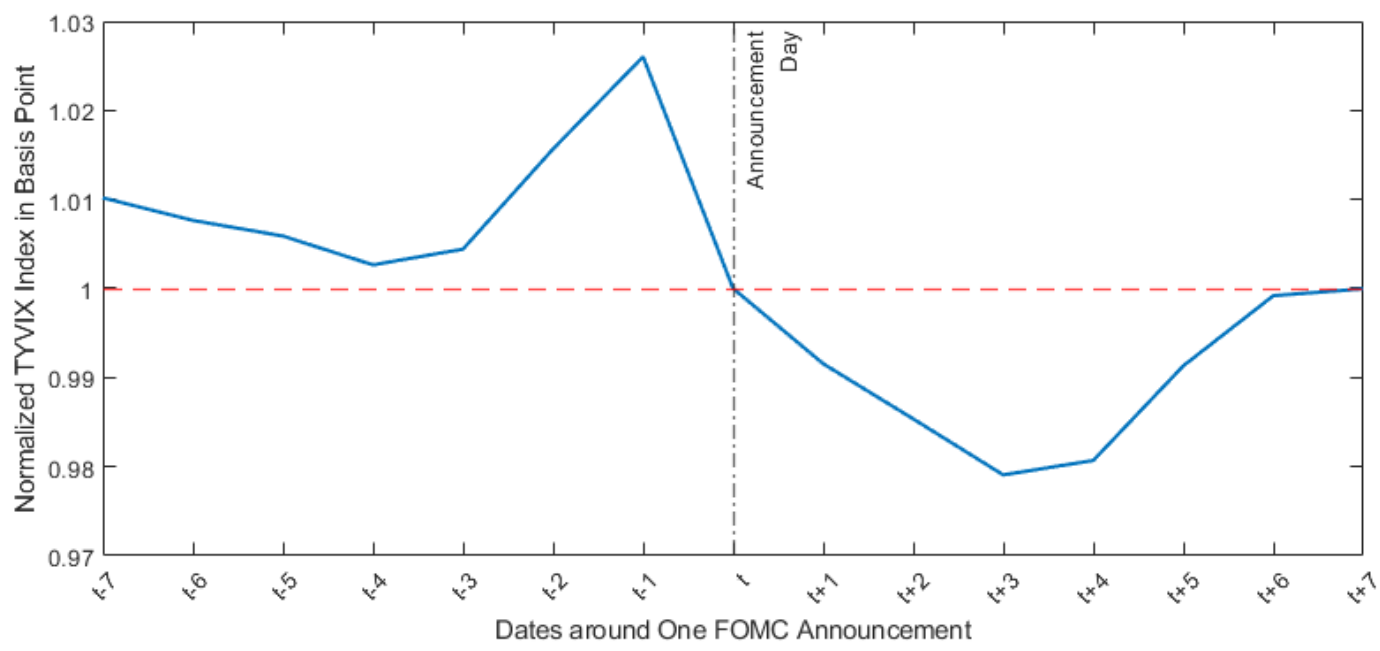

Figure 5: Averaged TYVIX Index from -7D to +7D of FOMC Decisions (Basis Point).

In Figure 5, we plot the TYVIX in basis point on 15 days around a "typical" FOMC announcement, averaging data around all FOMC meetings from 2003:1 to 2018:1. The 15 days are seven days before, the announcement date, and seven days after an announcement). ${ }^{14}$

Before an FOMC meeting, the TYVIX in basis point, on average, accumulates consecutively since four days before the announcement and then quickly ease back on the announcement date. This drift may be analogous to the fixed effect of FOMC events. It might not be relevant to the information content of monetary policy as this drift happens before a "typical" FOMC announcement.

We further investigate the institutional mechanism of this pre-FOMC-event drift in the volatility that roughly starts from 4 days prior to an FOMC announcement. We find its association with the timing of an FOMC announcement in a week. In Table 4, we list the weekday distribution of FOMC announcement dates. In the whole sample from 2003 to 2018, the majority of FOMC decisions (92\%) are announced on Tuesday, Wednesday, and Thursday. Four days before those weekdays are respectively Friday, Saturday and Sunday. As weekends are non-trading days for major exchanges, the data on Saturdays and Sundays are identical with closing quotes on the nearest precedent Fridays. Therefore, the TYVIX data in four days before the $92 \%$ of FOMC announcements points to closing quotes on Fridays in preceding weeks. In other words, the 4-day time window essentially takes the difference of the ending quote on Friday preceding one announcement and the ending quote on the announcement date.

\footnotetext{
${ }^{14}$ We use actual dates rather than trading dates in Figure 5, but our data is recorded only on trading days. Therefore, our data source fills the empty data points of weekends and holidays with the nearest precedent trading day data. For example, the data input for Saturday and Sunday is the same as the input for Friday.
} 
Table 4: Weekday Convention of FOMC Announcements

\begin{tabular}{lcccccccc}
\hline & Mon & Tue & Wed & thu & Fri & Sat & Sun & Total \\
\hline Sample Counts & 5 & 40 & 81 & 10 & 3 & 1 & 1 & 140 \\
Percent & $4 \%$ & $28 \%$ & $57 \%$ & $7 \%$ & $2 \%$ & $1 \%$ & $0 \%$ & $100 \%$ \\
\hline
\end{tabular}

However, why do Fridays before announcement weeks become turning points of the TYVIX index? Chordia et al. (2001) among others investigate weekday effects of trading activities and indicate that Fridays often feature a significant decrease in trading volume and liquidity. Chen and Singal (2003) and Jones and Shemesh (2010) address a "Friday effect" with the reduction in demand and price of call and put options due to the downside risk of holding securities during weekends. The TYVIX index is calculated with the Treasury note options prices via Black-Sholes non-arbitrage formula. Therefore, decline in demand for call and put options leads to a lower figure of the TYVIX index on Fridays.

To verify the relationship between the pre-FOMC-announcement drift in the volatility and the Friday effect, in Figure 6, we further show time-averaged fluctuations in the TYVIX index in basis point for announcements on different weekdays. No matter which day (a Tuesday, Wednesday or Thursday) an FOMC statement is released, the TYVIX index reaches the trough in the preceding Friday. In the announcement week, trading volume and liquidity in options markets resume from the low point. This pattern suggests that the pre-FOMCannouncement drift is due to the Friday effect. Another interesting finding is that, on average, the interest rate volatility amplifies at a higher speed when approaching an FOMC event. This may be due to more unofficial market rumors and trading on interest rate uncertainty before official news release. In short, the pre-FOMC-announcement drift seems to commence at the beginning of an announcement week and gain momentum when approaching the FOMC press conference.

For our purpose, we attempt to capture the exogenous impact of monetary policy rather than the effects of upcoming FOMC meetings. Therefore, we strive to minimize the noise introduced by the event-driven, pre-FOMC-announcement drift. We take advantage of the Friday effect to facilitate this practice.

In detail, the trading positions of options established after a weekend are more or less related to two types of short-term trading activities. First is the short-term hedge for the interest rate volatility caused by an FOMC event. An approaching FOMC meeting induces short-term uncertainty in interest rates. Risk-avoiding bond investors may enhance appetite for hedging, leading to the bid-up of options prices. The other activity is the short-term speculation on an FOMC decision. Speculation on possible interest rate changes may heat 


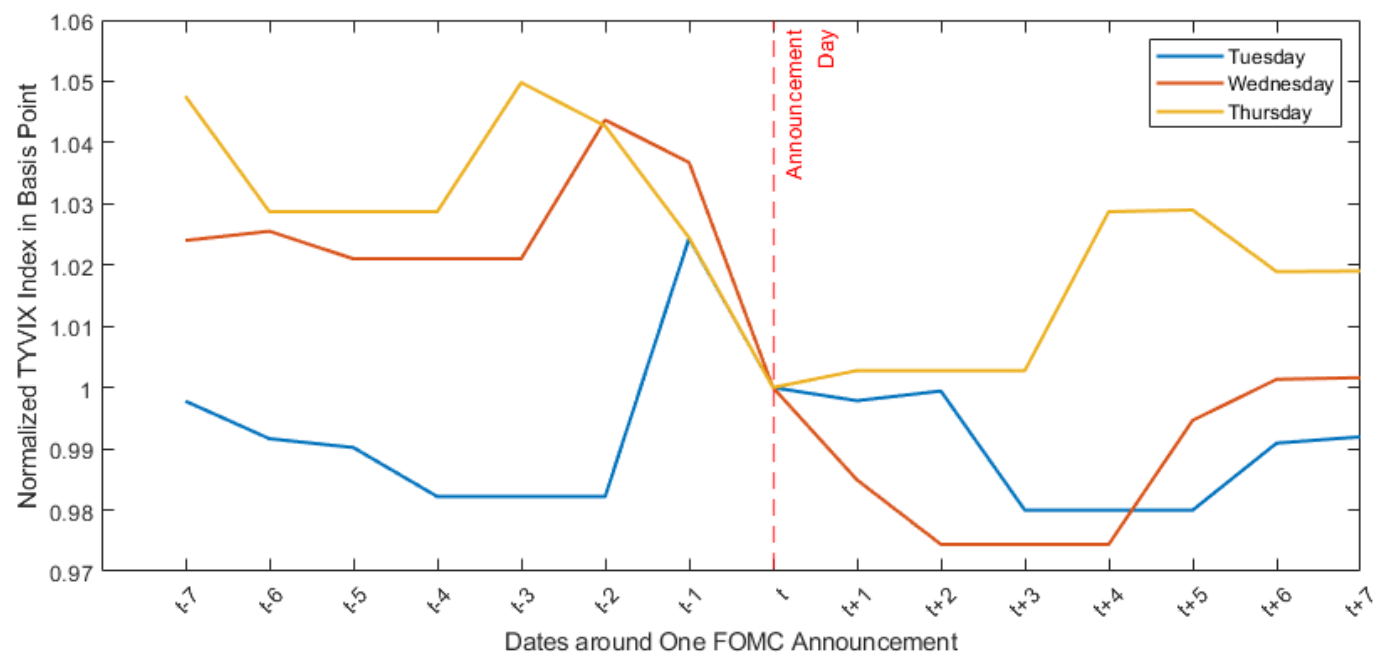

Figure 6: Averaged TYVIX Index for Announcements on Different Weekdays

up before an FOMC announcement. Both activities can temporarily drive up the demand for 10-year T-note options and the TYVIX index. The common characteristic of those tradings is a near-zero expected return that may not be adequate to compensate for the downside risk during the weekend. Therefore, those investors in aggregation should have limited gain from their expectation for monetary policy. Thus trade for or against the soaring volatility before an FOMC meeting. We attempt to diminish the impact of these trading activities.

In contrast, if other investors establish their options positions before or on the preceding Friday and hold during the weekend, their expectation for the upcoming FOMC decision is so strong that their expected returns on those positions overweight downside risk in the weekend. In other words, they gain from their expectation of monetary policy and their positions contribute to the expected component of monetary-policy-induced interest rate volatility. Consequently, only the positions established before, and held through, the weekend owns a tight relationship with the expectation of monetary policy.

To focus on changes in the expectation of monetary policy due to the information content of FOMC announcements, we determine both ends of the time window in light of the Friday effect. In terms of the leading end, the Friday preceding a policy decision has the least FOMC-event-driven trading positions of 10-year T-note options, in avoidance of the downside risk during the weekend. More importantly, the ending quote on Friday captures the volatility attributed to the expectation of monetary policy. It is because the corresponding options positions have adequately high expected return to tolerate the risk in the weekend. For the trailing end, the short-term hedging and speculation may halt right af- 
ter an FOMC announcement because the short-term uncertainty on interest rates may be principally resolved by the public statement of an interest rate decision.

Consequently, we take the difference of the TYVIX index between the closing quotes on Fridays before announcements and the closing quotes on the announcement dates. The two ends of this time window thus are, in the highest degree, unaffected by FOMC-event-driven, short-term trading activities. Captured changes of expected volatility in the long rate may solely attribute to the difference between expected and actual monetary policy.

Pragmatically, instead of frequently adjusting time windows, we measure monetarypolicy-driven changes in the interest rate volatility with a unified 4-day time window. In detail, for each FOMC meeting, we subtract the closing quote of TYVIX index in basis point on the fourth day prior to the FOMC announcement from the closing quote on the announcement date. Then we record this difference on the FOMC announcement date. Using this 4-day time window can accurately captures the impact of $92 \%$ of FOMC decisions in our sample (i.e., the FOMC announcements made on Tuesday, Wednesday and Thursday) because the four days before those weekdays all point to ending quotes on preceding Fridays.

We measure the unexpected change of the TYVIX index for each FOMC announcement (shown in Figure 7) and generate the event-study volatility surprise. Data points in the volatility surprise represent changes in the TYVIX index in basis point during the unified 4-day time windows around FOMC announcements. A positive volatility surprise indicates that a policy announcement induces an increase in the expected volatility of long-term rate and vice versa. To fit the volatility surprise in our monthly SVAR model, we convert it into a monthly time series following a procedure discussed in Appendix C (The monthly series is also shown in Figure 7).

Furthermore, we make minor adjustments to the time windows for FOMC announcements released on weekdays other than Tuesday, Wednesday and Thursday. For the decisions on Mondays, we narrow time windows into three days to set the leading end of time windows to be Friday. As to the FOMC announcements made during the weekend, we extend the trailing end of time windows to the ensuing Mondays in order to let financial markets to price in those announcements. In total, we adjust the time windows for 6 out of $140 \mathrm{FOMC}$ meetings in our sample. 15

Admittedly, a potential drawback of a relatively wide time window is that it may include the impact of economic news other than monetary policy decisions. However, event studies for interest rate volatility are different from those for level data. We may be unnecessary to rule out the impact of economic news as attempted by tight time window settings in literature, such as 30 minutes or shorter. Instead, we make a less restrictive assumption

\footnotetext{
${ }^{15}$ The results are robust without adjustments.
} 


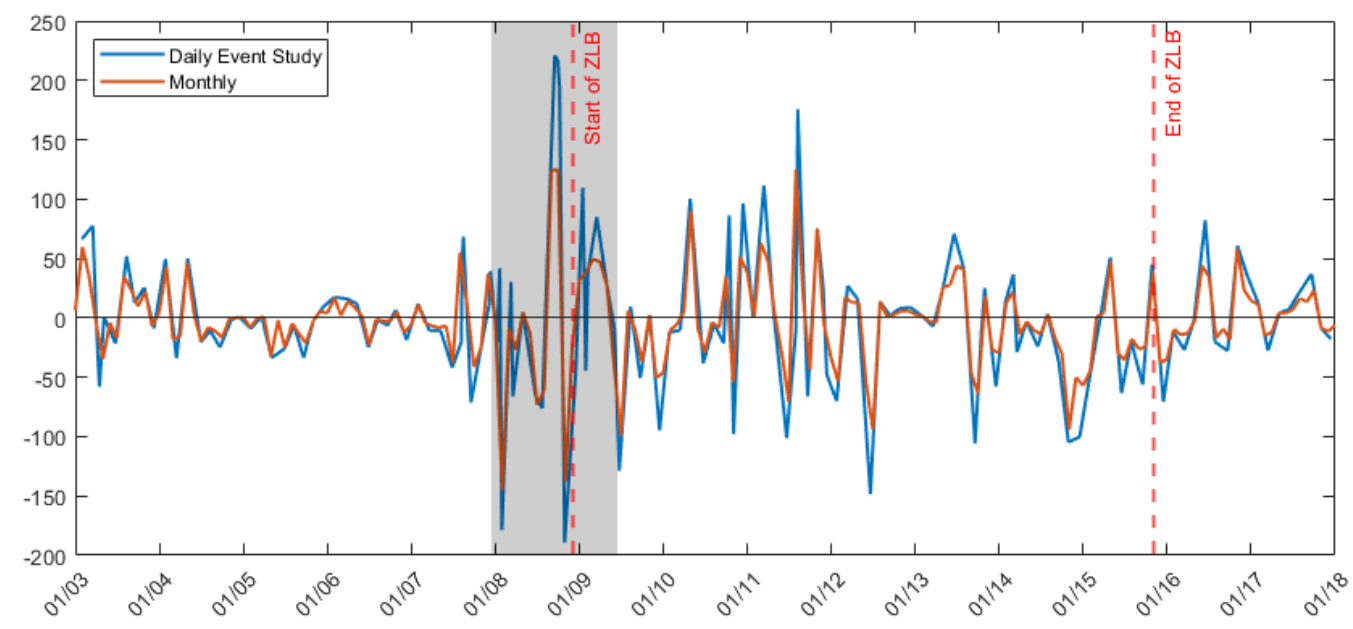

Figure 7: The Volatility Surprise (Basis Point; Event Study and Monthly)

on the frequency of economics news. If economic news is frequently released and has the same occurrence probability on dates approximating to a time window, the contribution of economics news to interest rate volatility is relatively stable around this time window and can be canceled out when taking the difference. As a result, if the TYVIX index in basis point is different at the two ends of a time window, the difference should be ascribed to the varying expectation after an FOMC announcement. This assumption renders us a potentially wider time window, i.e., the 4-day window, because we maybe not obliged to purge all noises from economic news.

In Table 5, we look at the relationship between volatility surprises captured by various time windows and unconventional monetary tools. Specifically, we regress volatility surprises captured by different time windows on the dummy variables of announcements related to LSAPs and forward guidance. The dummies of unconventional policy tools are based on narratives in FOMC statements. To retain consistency with the literature, we adopt identical narratives as Swanson (2017). Since almost all FOMC announcements contain sentences regarding forward guidance, we only include those announcements that change the communication styles in the forward guidance dummy, for instance, the change from a calendar threshold to an outcome-based threshold. Since the Federal Reserve only implements those unconventional tools during the ZLB period, we truncate the sample to that period. As to the exogeneity issue, we consider a volatility surprise is a reaction of the bond market to an FOMC announcement, which includes information of those unconventional tools. Thus, we assume a contemporaneous unidirectional impact from announcements regarding unconventional tools to volatility surprises. 
Table 5: Comparison of the Time Windows for Volatility Surprises

\begin{tabular}{lccccc}
\hline & $1 \mathrm{D}$ & $2 \mathrm{D}$ & $3 \mathrm{D}$ & $4 \mathrm{D}$ & $5 \mathrm{D}$ \\
\hline FG & 27.073 & 54.644 & $68.639^{* *}$ & $73.915^{* *}$ & $73.915^{* *}$ \\
& $(22.395)$ & $(37.302)$ & $(34.062)$ & $(34.174)$ & $(34.174)$ \\
LASP & $-68.657^{* * *}$ & $-72.656^{* * *}$ & $-74.980^{* * *}$ & $-71.463^{* * *}$ & $-71.463^{* * *}$ \\
& $(16.598)$ & $(22.758)$ & $(22.155)$ & $(22.271)$ & $(22.271)$ \\
\hline Obs. & 88 & 88 & 88 & 88 & 88 \\
$R^{2}$ & -0.228 & 0.061 & 0.100 & 0.112 & 0.107 \\
\hline
\end{tabular}

$* p<0.05,{ }^{* *} p<0.01,{ }^{* * *} p<0.001$

Note: HAC Robust standard errors in parentheses

Table 5 shows the superiority of the four-day time window, as volatility surprises captured by the 4-day time window has the highest correlation with announcements of unconventional monetary policy tools than those measured in tighter or wider time windows. It confirms our hypothesis that the pre-FOMC-announcement drift in the volatility produces more noise, rather than reflects more information of monetary policy, in producing the volatility surprise.

Interpretation of those coefficients provides us additional insight in properties of the volatility surprise. LSAPs are associated with negative volatility surprises, indicating that an expansionary policy announcement reduces the perceived risk of long-term rate. Noteworthily, I may not attribute the cause of negative volatility surprises to policy rate changes that may be happened simultaneously with unconventional policy actions. During the ZLB period, the policy rate is essentially zero and changes of the policy rate, either expected or unexpected, are minimal comparing with its fluctuation during normalized interest rate periods. In contrast, volatility surprises are larger in magnitude during the ZLB period. Thus, negative volatility surprises are more attributable to LSAPs, rather than to possible unexpected changes in the policy rate that coincide with those expansionary assets purchases. Our finding that LSAPs and policy rate cuts similarly lead to negative volatility surprises is consistent with the results in a working paper Mallick et al. (2017). They use a VAR model with Cholesky identification as well as sign restrictions to find that a conventional policy rate cut and an LSAP both lead to the negative response of bond yield volatility. As to forward guidance, a change in communication styles is generally correlated with a positive volatility surprise. Lakdawala (2016) and Kim (2017) both find that forward guidance shocks are contractionary. The public may perceive more variation in future monetary policy shocks due to shifts in communication approaches. In Appendix D, we provide additional details on the connection between volatility surprises and unconventional monetary policy tools. A forward guidance that confirms a previously set threshold tends to relate with a negative 
volatility surprise.

Through an event study featuring the 4-day time window and the utilization of TYVIX index, We obtain the event-study volatility surprise. Eventually, we convert it into a monthly series and identify monetary policy shocks from a risk-taking channel perspective.

\section{Conclusion}

Monetary policy is multi-dimensional, and it contains more information than what may be explicit by policy rate movements. The introduction of unconventional monetary policy tools shifts our attention to policy influences in longer-term interest rates. To incorporate the entire policy impact on the whole yield curve, we introduce a long-term interest rate as the policy indicator into an otherwise standard monetary SVAR. In order to identify monetary policy shocks from long-term rate fluctuations, we construct an event study from the variation of interest rate volatility around each FOMC announcement and use the resulting time series as an external instrument.

We estimate an empirical SVAR model to evaluate the validity of the conventional Keynesian interest rate channel and the less-explored risk-taking channel within a single framework. We find merits in the external instrument and heteroskedasticity identification approaches. Thus, we combine elements from both in our analysis. Furthermore, we introduce a first attempt to quantify the monetary-policy-induced variation in the perceived interest rate risk in financial markets supported by an event study.

Two relatively independent transmission mechanisms are identified through the two ends of the yield curve. Both avenues converge in the similar responses of financial frictions and output. We conclude the interest rate volatility is a critical ingredient in identifying monetary policy shocks from movements in the long-term real interest rate. While the transmission through the conventional Keynesian interest rate channel is unobservable, we obtain evidence consistent with the risk-taking channel and review the viability of the credit channel.

Our analysis does not constitute a call for a different instrument of monetary policy, given the difficulty of accurately targeting the public's perception of interest rate volatility, particularly on the long end of the yield curve. Instead, we provide a tool for market participants to analyze the potential impact of policy on long-term rates from a risk-taking channel perspective. This paper underscores the need for further exploration in the role of long-term interest rates in the transmission mechanism of monetary policy. 


\section{References}

Adrian, T., Crump, R.K., Moench, E., 2013. Pricing the term structure with linear regressions. Journal of Financial Economics 110, 110-138.

Adrian, T., Shin, H.S., 2008. Liquidity, monetary policy, and financial cycles. Current issues in economics and finance 14 .

Altunbas, Y., Gambacorta, L., Marqués-Ibanez, D., 2009. An empirical assessment of the risk-taking channel. Available at SSRN 1459627.

Bagliano, F.C., Favero, C.A., 1999. Information from financial markets and var measures of monetary policy. European Economic Review 43, 825-837.

Baker, S.R., Bloom, N., Davis, S.J., 2016. Measuring economic policy uncertainty. The Quarterly Journal of Economics 131, 1593-1636.

Bekaert, G., Hoerova, M., Lo Duca, M., 2013. Risk, uncertainty and monetary policy. Journal of Monetary Economics 60, 771-788.

Bernanke, B.S., 2013. Communication and monetary policy: a speech at the national economists club annual dinner, herbert stein memorial lecture, washington, dc, november 19, 2013.

Bernanke, B.S., Gertler, M., 1995. Inside the black box: the credit channel of monetary policy transmission. Journal of Economic perspectives 9, 27-48.

Bernanke, B.S., Gertler, M., Gilchrist, S., 1999. The financial accelerator in a quantitative business cycle framework. Handbook of macroeconomics 1, 1341-1393.

Blinder, A.S., 2018. Through a crystal ball darkly: The future of monetary policy communication .

Blinder, A.S., Maccini, L.J., 1991. The resurgence of inventory research: what have we learned? Journal of Economic Surveys 5, 291-328.

Borio, C., Zhu, H., 2012. Capital regulation, risk-taking and monetary policy: a missing link in the transmission mechanism? Journal of Financial Stability 8, 236-251.

Bruno, V., Shin, H.S., 2015. Capital flows and the risk-taking channel of monetary policy. Journal of Monetary Economics 71, 119-132. 
Bundick, B., Herriford, T., Smith, A., 2017. Forward guidance, monetary policy uncertainty, and the term premium. Research Working Paper RWP 17-7 .

Campbell, J.R., Evans, C.L., Fisher, J.D.M., Justiniano, A., 2012. Macroeconomic effects of federal reserve forward guidance. Brookings Papers on Economic Activity 2012, 1-80.

Carlson, J.B., Craig, B.R., Melick, W.R., 2005. Recovering market expectations of fomc rate changes with options on federal funds futures. Journal of Futures Markets 25, 1203-1242.

Chen, H., Singal, V., 2003. Role of speculative short sales in price formation: The case of the weekend effect. The Journal of finance 58, 685-705.

Chirinko, R.S., 1993. Business fixed investment spending: Modeling strategies, empirical results, and policy implications. Journal of Economic literature 31, 1875-1911.

Chordia, T., Roll, R., Subrahmanyam, A., 2001. Market liquidity and trading activity. The Journal of finance 56, 501-530.

Christensen, B.J., Prabhala, N.R., 1998. The relation between implied and realized volatility1. Journal of Financial Economics 50, 125-150.

Christiano, L.J., Eichenbaum, M., Evans, C.L., 1999. Monetary policy shocks: What have we learned and to what end? Handbook of macroeconomics 1, 65-148.

Christiano, L.J., Trabandt, M., Walentin, K., 2010. Dsge models for monetary policy analysis, in: Handbook of monetary economics. Elsevier. volume 3, pp. 285-367.

Cochrane, J.H., Piazzesi, M., 2002. The fed and interest rates-a high-frequency identification. American economic review 92, 90-95.

Cœuré, B., 2017. Central bank communication in a low interest rate environment. Open Economies Review 28, 813-822.

d'Amico, S., English, W., López-Salido, D., Nelson, E., 2012. The federal reserve's large-scale asset purchase programmes: rationale and effects. The Economic Journal 122, F415-F446.

Delis, M.D., Hasan, I., Mylonidis, N., 2012. The risk-taking channel of monetary policy in the usa: Evidence from micro-level data. Available at SSRN 2013787.

Dell'Ariccia, G., Laeven, L., Suarez, G.A., 2017. Bank leverage and monetary policy's risktaking channel: evidence from the united states. The Journal of finance 72, 613-654. 
Eberly, J., Stock, J.H., Wright, J.H., 2019. The federal reserve's current framework for monetary policy: A review and assessment. NBER Working Paper .

Eichenbaum, M., 1992. Comments" on "interpreting the macroeconomic time series facts: The effects of monetary policy" by c. sims. European Economic Review , 1001-1011.

Emmons, W.R., Lakdawala, A.K., Neely, C.J., 2006. What are the odds? option-based forecasts of fomc target changes. Federal Reserve Bank of St. Louis Review , 543-562.

Faust, J., Swanson, E.T., Wright, J.H., 2004. Identifying vars based on high frequency futures data. Journal of Monetary Economics 51, 1107-1131.

Fleming, J., 1998. The quality of market volatility forecasts implied by s\&p 100 index option prices. Journal of empirical finance 5, 317-345.

Fleming, J., Ostdiek, B., Whaley, R.E., 1995. Predicting stock market volatility: A new measure. Journal of Futures Markets 15, 265-302.

Freedman, C., 1994. The use of indicators and of the monetary conditions index in canada. Frameworks for monetary stability: policy issues and country experiences , 458-476.

Gagnon, J., 2010. Large-Scale Asset Purchases by the Federal Reserve: Do They Work? DIANE Publishing.

Gagnon, J., Raskin, M., Remache, J., Sack, B., 2011. The financial market effects of the federal reserve's large-scale asset purchases. international Journal of central Banking 7, $3-43$.

Gambacorta, L., 2009. Monetary policy and the risk-taking channel. BIS Quarterly Review December .

Gertler, M., Karadi, P., 2015. Monetary policy surprises, credit costs, and economic activity. American Economic Journal: Macroeconomics 7, 44-76.

Gilchrist, S., Zakrajšek, E., 2012. Credit spreads and business cycle fluctuations. American economic review 102, 1692-1720.

Gürkaynak, R.S., Sack, B., Swanson, E., 2005. The sensitivity of long-term interest rates to economic news: Evidence and implications for macroeconomic models. American economic review 95, 425-436. 
Gurkaynak, R.S., Sack, B.P., Swanson, E.T., 2004. Do actions speak louder than words? the response of asset prices to monetary policy actions and statements .

Hamilton, J.D., 2008. Daily monetary policy shocks and new home sales. Journal of Monetary Economics 55, 1171-1190.

Hanson, S.G., Stein, J.C., 2015. Monetary policy and long-term real rates. Journal of Financial Economics 115, 429-448.

Husted, L.F., Rogers, J.H., Sun, B., 2017. Monetary policy uncertainty .

Jones, C.S., Shemesh, J., 2010. The weekend effect in equity option returns. Unpublished Working Paper. University of Southern California .

Jorda, O., 2005. Can monetary policy influence long-term interest rates? FRBSF Economic Letter .

Keating, J.W., Kelly, L.J., Smith, A.L., Valcarcel, V.J., 2019. A model of monetary policy shocks for financial crises and normal conditions. Journal of Money, Credit and Banking $51,227-259$.

Keating, J.W., Kelly, L.J., Valcarcel, V.J., 2014. Solving the price puzzle with an alternative indicator of monetary policy. Economics Letters 124, 188-194.

Kim, D.H., Wright, J.H., 2005. An arbitrage-free three-factor term structure model and the recent behavior of long-term yields and distant-horizon forward rates .

Kim, K., 2017. Identification of monetary policy shocks with external instrument svar .

Krippner, L., 2013. Measuring the stance of monetary policy in zero lower bound environments. Economics Letters 118, 135-138.

Kuttner, K.N., 2001. Monetary policy surprises and interest rates: Evidence from the fed funds futures market. Journal of Monetary Economics 47, 523-544.

Lakdawala, A., 2016. Decomposing the effects of monetary policy using an external instruments svar. Journal of applied econometrics .

Lombardi, M., Zhu, F., 2014. A shadow policy rate to calibrate us monetary policy at the zero lower bound .

Lucca, D.O., Moench, E., 2015. The pre-fomc announcement drift. The Journal of finance $70,329-371$. 
Mallick, S., Mohanty, M.S., Zampolli, F., 2017. Market volatility, monetary policy and the term premium .

Melosi, L., 2016. Signalling effects of monetary policy. The Review of Economic Studies 84, 853-884.

Mertens, K., Ravn, M.O., 2013. The dynamic effects of personal and corporate income tax changes in the united states. American economic review 103, 1212-1247.

Nakamura, E., Steinsson, J., 2018. High-frequency identification of monetary non-neutrality: the information effect. The Quarterly Journal of Economics 133, 1283-1330.

Rajan, R.G., 2006. Has finance made the world riskier? European Financial Management 12, 499-533.

Rigobon, R., 2003. Identification through heteroskedasticity. Review of Economics and Statistics 85, 777-792.

Rigobon, R., Sack, B., 2003. Measuring the reaction of monetary policy to the stock market. The Quarterly Journal of Economics 118, 639-669.

Rigobon, R., Sack, B., 2004. The impact of monetary policy on asset prices. Journal of Monetary Economics 51, 1553-1575.

Romer, C.D., Romer, D.H., 2000. Federal reserve information and the behavior of interest rates. American economic review 90, 429-457.

Rosa, C., 2012. How'unconventional'are large-scale asset purchases? the impact of monetary policy on asset prices .

Stein, J.C., 1989. Efficient capital markets, inefficient firms: A model of myopic corporate behavior. The Quarterly Journal of Economics 104, 655-669.

Stock, J., Yogo, M., 2005. Asymptotic distributions of instrumental variables statistics with many instruments. Chapter.

Stock, J.H., Watson, M.W., 2012. Disentangling the channels of the 2007-2009 recession .

Svensson, L.E.O., 1999a. Inflation targeting as a monetary policy rule. Journal of Monetary Economics 43, 607-654.

Svensson, L.E.O., 1999b. Inflation targeting: some extensions. The Scandinavian Journal of Economics 101, 337-361. 
Swanson, E.T., 2006. Have increases in federal reserve transparency improved private sector interest rate forecasts? Journal of Money, Credit and Banking 38, 791-819.

Swanson, E.T., 2015. Measuring the effects of unconventional monetary policy on asset prices .

Swanson, E.T., 2017. Measuring the effects of federal reserve forward guidance and asset purchases on financial markets .

Swanson, E.T., Williams, J.C., 2014. Measuring the effect of the zero lower bound on medium-and longer-term interest rates. American economic review 104, 3154-3185.

Weale, M., Wieladek, T., 2016. What are the macroeconomic effects of asset purchases? Journal of Monetary Economics 79, 81-93.

Woodford, M., 2012. Methods of policy accommodation at the interest-rate lower bound. The Changing Policy Landscape 185, 288.

Wright, J.H., 2012. What does monetary policy do to long-term interest rates at the zero lower bound? The Economic Journal 122.

Wu, J.C., Xia, F.D., 2016. Measuring the macroeconomic impact of monetary policy at the zero lower bound. Journal of Money, Credit and Banking 48, 253-291. 


\section{A Algorithm for identification}

Considering partitioning the mapping matrix between reduced-form residuals and structural shocks as

$$
S=\left[\begin{array}{ll}
s & S_{q}
\end{array}\right]=\left[\begin{array}{ll}
s_{11} & s_{12} \\
s_{21} & s_{22}
\end{array}\right]
$$

and the reduced-form variance-covariance matrix as

$$
\Sigma=\left[\begin{array}{ll}
\Sigma_{11} & \Sigma_{12} \\
\Sigma_{21} & \Sigma_{22}
\end{array}\right]
$$

Since structural shocks are normalized, $E\left[u_{t} u_{t}^{\prime}\right]=E\left[S S^{\prime}\right]=\Sigma$ and $\Sigma$ is symmetric. Therefore,

$$
\left(\Sigma_{21}-\frac{s_{21}}{s_{1} 1} \Sigma_{11}\right)^{\prime}\left(\Sigma_{21}-\frac{s_{21}}{s_{1} 1} \Sigma_{11}\right)=s_{12} Q s_{12}^{\prime}
$$

with

$$
Q=\frac{s_{21}}{s_{1} 1} \Sigma_{11}\left(\frac{s_{21}}{s_{1} 1}\right)^{\prime}-\left(\Sigma_{21}\left(\frac{s_{21}}{s_{1} 1}\right)^{\prime}+\frac{s_{21}}{s_{1} 1} \Sigma_{21}^{\prime}\right)+\Sigma_{22}
$$

The contemporaneous response of the policy indicator to a unit increase of monetary policy shocks $s^{p}$ is derived from the underlying closed form solution.

$$
\left(s^{p}\right)^{2}=s_{11}^{2}=\Sigma_{11}-s_{12} s_{12}^{\prime},
$$

where the portion of reduced-form variance of the policy indicator attributed to other structural shocks

$$
s_{12} s_{12}^{\prime}=\left(\Sigma_{21}-\frac{s_{21}}{s_{1} 1} \Sigma_{11}\right)^{\prime} Q^{-1}\left(\Sigma_{21}-\frac{s_{21}}{s_{1} 1} \Sigma_{11}\right)
$$

With the estimated $\frac{s_{21}}{s_{11}}$ in the second-stage regression and $\Sigma$ in reduced form VAR, we obtain the estimate of $\mathrm{s}$ vector. 


\section{B Supporting material for matching volatility surprises with lagged VAR resid- uals in the equation of policy indicator}

A concern about the non-contemporaneous matching is that historical values of the policy indicator seem predictive for volatility surprises so that identified monetary policy shocks might reflect systematic component of monetary policy. However, we find no evidence to bolster this arguement in the daily date analysis and Granger causality test.

Table 6 shows that volatility surprises are not predictable by 10-year TIPS yield movements within one week before 4-day time windows. Whereas, volatility surprises motivate significant fluctuations in long-term TIPS yield and the impact is relatively persistent.

Table 6: Real yield effects of volatility surprises (daily event study, 2003-2018)

\begin{tabular}{lcccccccc}
\hline & Week before & \multicolumn{3}{c}{ 1-week } & & \multicolumn{3}{c}{ 2-week } \\
Maturity (Real Yield) & $10 \mathrm{Y}$ & $2 \mathrm{Y}$ & $5 \mathrm{Y}$ & $10 \mathrm{Y}$ & & $2 \mathrm{Y}$ & $5 \mathrm{Y}$ & $10 \mathrm{Y}$ \\
\hline VOL & -1.231 & 0.051 & $0.043^{* *}$ & $0.041^{* * *}$ & $0.137^{* * *}$ & $0.074^{* * *}$ & $0.057^{* *}$ \\
& $(-0.882)$ & $(1.448)$ & $(1.898)$ & $(2.717)$ & & $(2.068)$ & $(2.63)$ & $(2.308)$ \\
\hline$R^{2}$ & 0.014 & 0.066 & 0.088 & 0.116 & & 0.156 & 0.133 & 0.112 \\
\hline
\end{tabular}

Note: ${ }^{*} p<0.05,{ }^{* *} p<0.01,{ }^{* * *} p<0.001$. Robust t-statistic in parentheses.

Cumulative changes of Treasury real yields in the weeks before announcements as well as those changes in one week (and two weeks) after announcements.

The standard deviation of volatility surprise is normalized to 1 .

In the second colume, the volatility surprise is the dependent variable.

Table 7 indicates the Granger causality between volatility surprises and reduced-form VAR residual in the policy indicator equation. Importantly, we pair volatility surprises with contemporaneous policy indicator residuals. The result strongly support the unidirectional impact of volatility surprises on policy indicator residuals.

Table 7: Pairwise Granger Causality Test

\begin{tabular}{lccc}
\hline Null Hypothesis: & Obs. & F-statistic & Prob. \\
\hline VOL does not Granger Cause Policy Indicator Residual & 176 & 5.642 & 0.001 \\
Policy Indicator Residual does not Granger Cause VOL & & 0.344 & 0.793 \\
\hline
\end{tabular}

Note: The policy indicator is 10-year TIPS yield. VAR residuals of the policy indicator are contemporaneous with volatility surprises in the test. 
Consequently, we attribute the mismatching to the conversion procedure from daily to monthly times series and the persistent impact of volatility surprises on the long-term real yield.

\section{Conversion of the event-study volatility surprise to monthly time series}

Most macro-economic variables are measured in monthly or lower frequencies. In order to infer with macroeconomic variables in our monthly SVAR model, we convert the event-study time series into a monthly series in three steps. First, we arrange all event-study volatility surprises on a daily time axis according to their respective announcement dates. As the TYVIX index measures the 30-day implied volatility of the long rate, a volatility surprise shows the difference of investors' expectation of long rate volatility measured for the future 30 days due to an FOMC announcement. Thus, we set the impact horizon of a volatility surprise as 30 days to match the time length of the expectation. Second, in case of the 30day impacts of two volatility surprises partially overlapped, we integrate the two surprises based on their respective FOMC announcement dates and sum up the overlapped portion. This circumstance may incurs between an unscheduled and a scheduled FOMC meetings, or between two unscheduled meetings. Third, we add up the impacts of volatility surprises on each day of a month and divide the sum with number of days in a month (i.e. 30 days). Consequently, we derive the monthly volatility surprise as shown in Figure 8.

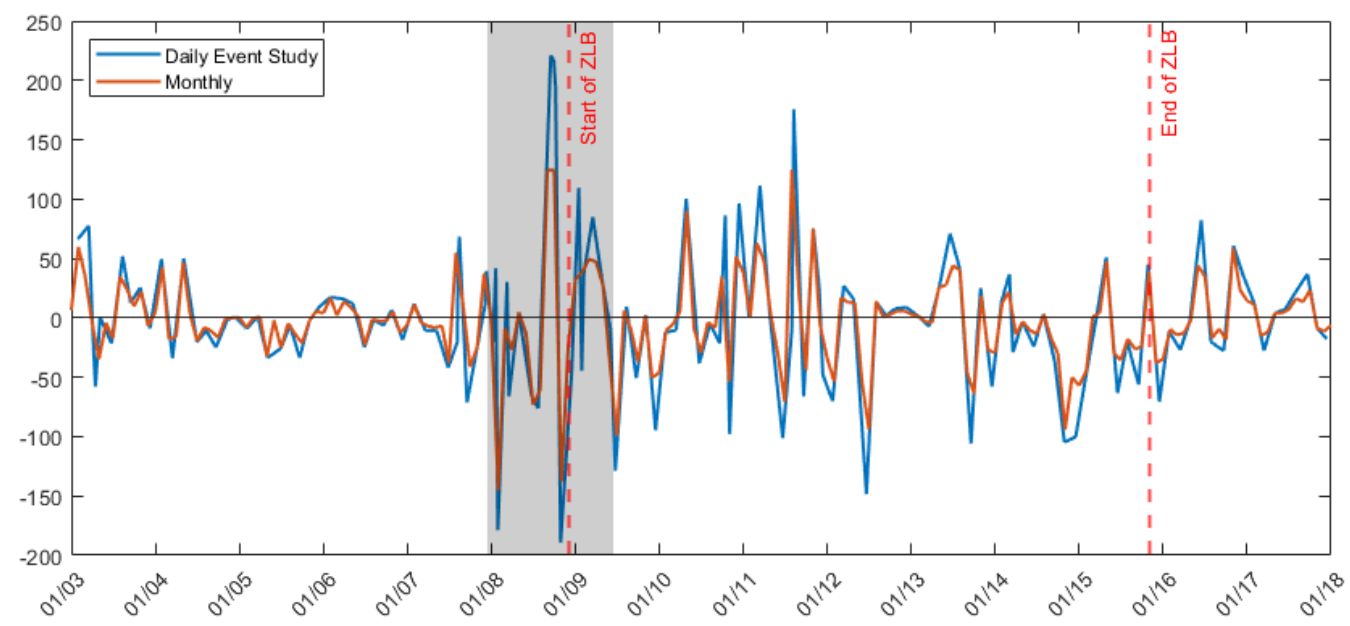

Figure 8: The Volatility Surprise (Monthly \& Daily; Basis Point)

Overall, the monthly volatility surprise retains the features of the event-study time series, such as the timing of peaks and troughs, the mean reverting property, etc. However, in monthly series, we notice that one positive spike on October 2008, which amounts to more 
than 8 times of sample standard deviation, is more prominent than its counterpart in eventstudy series. As shown in Figure 8, we truncate the data on October 2008 to the same level as that on September 2008 to diminish the distortion. The distinctive spike is due to the different ways of recording volatility surprise impacts in the two series. Near the October 2008, two emergent unscheduled FOMC meetings were held on September 29th and October 7th. Both meetings induce large positive volatility surprises, indicating the policy actions announced after those meetings aggravate the long-term perceived risk in interest rates. Those meetings are less-than-30-day apart. In the event-study series, the impacts of those meetings are parallelly registered on their respective dates and do not intervene with each other. In contrast, the monthly time series lengthen the impacts of volatility surprises to 30 days and adds up the overlapped impacts of two meetings with less than 30-day interval. Therefore, if two or more FOMC meetings are closely adjoined and generate volatility surprises in an identical sign, the monthly time series may be distorted by the resulting extremely large spike. This phenomenon is prominent in October 2008 and a truncation is applied to restore the distortion.

Admittedly, this conversion approach may fall short in identifying the timing of events. For example, if an FOMC announcement is made at the end of month $t$. In event-study time series, this volatility surprise is in the month t. However, in monthly conversion, since the 30 days after the meeting majorly locate in month $t+1$, the principle volatility surprise is recorded in month $t+1$, rather than in the month when it actually happens. This shortcoming partially explains why the monthly volatility surprise matches better with the lagged VAR residual of the policy indicator. 


\section{The volatility surprise and unconventional monetary policy tools}

The volatility surprise provide us insight in the risk-side impact of unconventional monetary policy tools. Table 8 shows that changing forward guidance communication style is often associated with a positive volatility surprise. The public may perceive more variation in future monetary policy shocks due to shifts in communication approach. In general, announcements of LSAPs lead to negative voaltility surprises as LSAPs reconfirm the goal of monetary policy, which is to curtail the downside economic risk. More interestingly, the gradual exit of balance sheet approaches also causes negative volatility surprises. However, these may not contribute to reduction in monetary easing; instead, they may be attributed to the improvement of economic prospect.

Table 8: Reactions of the Volatility Surprise to Important Policy Changes (Event Study)

\begin{tabular}{ccc}
\hline Dates & Communication & Volatility Surpirse \\
\hline & Forward Guidance \\
$2009 / 03 / 18$ & ZLB for an extended period & 1.397 \\
$2011 / 08 / 09$ & Adopt calendar threshold & 2.890 \\
$2012 / 01 / 25$ & Extend calendar threshold & -1.153 \\
$2012 / 09 / 13$ & Extend calendar threshold & 0.032 \\
$2012 / 12 / 12$ & Adopt outcome-based threshold & 0.146 \\
$2013 / 12 / 18$ & Confirm outcome-based threshold & -0.951 \\
$2014 / 03 / 19$ & Confirm outcome-based threshold & -0.476 \\
$2014 / 12 / 17$ & Confirm outcome-based threshold & -1.649 \\
\hline & & \\
$2008 / 10 / 29$ & LSAPs & -3.114 \\
$2010 / 09 / 21$ & Announce QE1 & -0.352 \\
$2010 / 11 / 03$ & Announce QE2 & -0.352 \\
$2011 / 09 / 21$ & Announce the Operational Twist & -1.087 \\
$2011 / 09 / 21$ & Announce QE3 & 0.032 \\
$2013 / 12 / 18$ & Slowing purchases & -0.951 \\
$2014 / 09 / 17$ & Balance sheet normalization & -0.601 \\
\hline
\end{tabular}

Note: Volatility surprises are normalized to unit standard deviation. 